\title{
CIENCIA JURÍDICA REALISTA: MODELOS Y JUSTIFICACIÓN*
}

\author{
Álvaro Núñez Vaquero \\ Universidad Carlos III de Madrid
}

RESUMEN. El presente trabajo persigue un triple objetivo: enmarcar las propuestas metodológicas realistas dentro de la teoría normativa de la ciencia jurídica, mostrar la variedad de modelos realistas de ciencia jurídica, y presentar algunas razones prácticas que justifican asumir alguno de dichos modelos. Para ello analizaré una forma de definir "ciencia jurídica" y ofreceré una redefinición de «ciencia jurídica» en sentido amplio. En segundo lugar, distinguiré entre doctrinas de la ciencia jurídica en sentido estricto y doctrinas de la dogmática jurídica. Una vez identificado el lugar que ocupa la ciencia jurídica realista en este marco conceptual, describiré cuatro modelos de ciencia jurídica realista: aquél de Ross, el de los situation-types del realismo estadounidense, el tarelliano y el New Legal Realism. Por último, ofreceré cuatro razones prácticas para realizar predicciones sobre cómo decidirán los jueces las futuras controversias.

Palabras clave: ciencia jurídica, dogmática jurídica, realismo jurídico, decisiones judiciales, predicciones y autonomía.

ABSTRACT. This paper aims three objectives: to frame realistic methodological proposals within the normative theory of legal science, to show the variety of realistic models of legal science, and to present some of the practical reasons that justify taking someone of these models. For this, I will analyze a way to define «legal science» and I will offer a re-definition of «legal science» ampio sensu. Secondly, I will distinguish between the doctrines of legal science in the strict sense and the doctrines of legal dogmatics. Having identified the place of realistic legal science in this conceptual framework, I will describe four models of realistic legal science: that of Ross, the situation-types of American realism, the tarellian model and the New Legal Realism. Finally, I will offer four practical reasons to make predictions about how judges will decide future controversies.

Keywords: legal science, legal dogmatics, legal realism, judicial decisions, predictions, autonomy.

* Fecha de recepción: 7 de noviembre de 2012. Fecha de aceptación: 21 de diciembre de 2012.

El presente trabajo fue escrito durante mi periodo como becario post-doctoral en la Universidad Carlos III de Madrid, durante el que estuve adscrito al Grupo de Investigación sobre el Derecho y la Justicia. Actualmente formo parte de la planta docente de la Universidad Austral de Chile.

Una versión precedente de este trabajo fue presentada en el XVII Seminario hispano-italiano-francés de Teoría del derecho, celebrado los días 21 y 22 de octubre de 2011 en la Universidad Carlos III de Madrid. 
«Siempre que se me ha requerido en los últimos años para opinar sobre el realismo me ha parecido necesario concluir de este modo —el realismo ha muerto- en aras del rigor académico o simplemente del respeto a la verdad. Sin embargo, debo confesar que, en lo más profundo de mi vocación como jurista, desearía que el realismo resucitara».

Liborio HIERRO

\section{SOBRE EL CONCEPTO DE «CIENCIA JURÍDICA»}

\subsection{Introducción al concepto de ciencia jurídica}

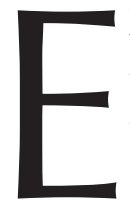

1 debate sobre la ciencia jurídica tiene la peculiaridad de colocarse puntualmente como centro del debate filosófico jurídico para, tiempo después, desaparecer. Si bien existen algunos indicios que hacen pensar que tal vez vuelva a emerger ${ }^{1}$, hoy en día el tema parece francamente abandonado. En los últimos años el tema incluso ha desaparecido de los programas de Filosofía del derecho de muchas universidades.

No obstante, se podría decir que la cuestión acerca de qué hacen (o deben hacer) los juristas nunca ha desaparecido del todo; es más, que siempre ha sido uno de los puntos centrales, o incluso el punto central, de todo el debate teórico-jurídico. Recordemos algunos célebres ejemplos: KELSEN afirma que la intención de su teoría pura es proporcionar un método para «elevar la ciencia del derecho [...] al nivel de una auténtica ciencia» (KELSEN, 2005: 7); Ross afirma querer desarrollar los principios empiristas hasta sus últimas consecuencias en el campo del conocimiento jurídico (ROSS, 1997: 17-18); HART afirma ocuparse «de la clarificación de la estructura general del pensamiento jurídico» (HART, 2004: XI); y el concepto de sistema normativo de ALCHOURRÓN y BULYGIN se presenta como una reconstrucción de lo que hacen los estudiosos del derecho positivo (AlCHOURRÓN Y BulYGIN, 1981: 25).

Sin embargo, pese a los ríos de tinta que se han vertido sobre cómo se conoce el derecho, se puede constatar una cierta actitud elusiva a la hora de definir «ciencia jurídica». Las dificultades para definir «ciencia jurídica» son bien conocidas: según $\mathrm{NINO}^{2}$, los dos términos que componen el sintagma son particularmente ambiguos y, además el segundo — «ciencia»— está cargado valorativamente y es vago en la mayoría de sus acepciones.

A los anteriores problemas podemos añadir los siguientes: i) la típica ambigüedad proceso-producto; ii) en ocasiones el término es usado al plural — «ciencias jurídicas»- para hacer referencia al conjunto de disciplinas que se ocupan de algún aspecto del derecho (FERRAJOLI, 2007: 8); iii) disponemos, en las lenguas neolatinas,

\footnotetext{
1 Me refiero, por ejemplo, a la publicación de Metbodologies of Legal Research (VAN HoECKE, 2011), que lleva precisamente por subtítulo Which Kind of Method for Which Kind of Discipline?, y al volumen colectivo editado hace algunos años por Ch. COURTIS (COURTIS, 2006).

2 Son dos los textos más importantes de Nino sobre teoría de la ciencia jurídica: NiNO, 1974 y 2003. Para un análisis de la teoría de la ciencia jurídica de NINO, vid. RoCA, 2008.
} 
de diferentes expresiones — «metodología jurídica», «ciencia del derecho», «doctrina jurídica», «dogmática jurídica», «jurisprudencia», etc.— aparentemente sinónimas pero que, en ocasiones, son usadas con significados parcialmente diferentes (RATTI, 2008: 205 y ss.); y iv) finalmente, la expresión «ciencia jurídica» es a veces usada para referirse exclusivamente a una o varias formas de estudiar el derecho que merecen ser calificadas como «científicas» (GUASTINI, 2011: 339 y ss.).

Ofrecer una definición de «ciencia jurídica» resulta pues necesario ya no tanto por una manía analítico-conceptual, sino por saber de qué estamos hablando cuando hablamos de «ciencia jurídica». Y es que si bien todos tenemos una cierta idea de a qué nos estamos refiriendo cuando hablamos de «ciencia jurídica», los malentendidos son innumerables en este ámbito.

Existen diferentes tipos de definiciones de «ciencia jurídica». Sin embargo, aquí me ocuparé sólo de un tipo de definición: aquellas que definen la «ciencia jurídica» como un conjunto de actividades. Veamos algunos ejemplos:

«Esta ciencia del derecho en sentido más estricto y propio es una mezcla de, al menos, tres actividades: 1) la descripción del derecho vigente; 2) su análisis sistemático y conceptual, y 3) la elaboración de propuestas para la solución de casos jurídicos problemáticos» (ALEXY, 1989: 240-241).

«Existe un tipo de investigación jurídica preponderante en los escritos jurídicos profesionales como manuales, monografías, comentarios y libros de texto que ponen en práctica un específico método jurídico que consiste en la sistemática, analítica y valorativa exposición de la sustancia del derecho privado, del derecho penal, del derecho público, etc. Aunque una exposición de este tipo puede contener consideraciones históricas, sociológicas, filosóficas y de otro tipo, su núcleo consiste en la descripción del sentido literal de las disposiciones, decisiones judiciales, etc., entrecruzadas con varias consideraciones morales y relativas a otras razones sustantivas. Es posible llamar a este tipo de exposición del derecho "doctrina jurídica"» (PECZENIK, 2007: 1).

«La dogmática jurídica es una actividad compleja en la que pueden y deben distinguirse tres etapas distintas: i) la identificación de las normas jurídicas; ii) la sistematización de tales normas, y iii) la modificación o transformación de los sistemas jurídicos» (BULYGIN, 1991: 466).

«[La ciencia jurídica] es definida, al menos en la tradición nórdica, como el estudio del contenido de las reglas (normas) jurídicas y del orden sistemático de aquéllas. Los términos usuales que se refieren a estas actividades son "interpretación" y "sistematización"» (AARNIO, 1191: 46-47).

«El núcleo duro de las ciencias jurídicas consiste en la elaboración de aparatos conceptuales relativos al derecho vigente (law in force), su sistematización, y a su aplicación e interpretación» (WROBLEWSKI, 1989: 14).

«Entenderemos por ciencia del derecho el saber que trata de describir las normas jurídico-positivas y que tradicionalmente se ha denominado dogmática jurídica o jurisprudencia» (CALSAMiglia, 1990: 12-13).

El problema de este tipo de definiciones es que, dicho en pocas palabras, meten el conejo en la chistera para después volverlo a sacar. En efecto, tales definiciones de ciencia jurídica suelen ser dependientes de algún concepto de derecho. Es decir, alguna definición acerca de la supuesta naturaleza del derecho o del criterio que supuestamente utilizarían los juristas para identificar los enunciados que, a continuación, analizarían (o deberían analizar) según un conjunto de directivas metodológicas. De este modo, la ciencia jurídica sería un conjunto de operaciones a realizar sobre un 
determinado objeto porque aquello que el derecho «es» determinaría cómo se tiene que estudiar ${ }^{3}$.

El hecho de que el concepto de «ciencia jurídica» sea dependiente de aquel de «derecho» no constituye, por supuesto, de por sí un problema. Ahora bien, lo que sí resulta problemático es pretender realizar afirmaciones acerca de qué hacen los estudiosos del derecho o qué es lo que deberían hacer a partir de una definición del concepto de «derecho»:

1. En primer lugar, si se trata de definiciones que pretenden dar cuenta de qué hacen realmente los estudiosos del derecho positivo, probablemente estemos frente a definiciones basadas en asunciones falsas, cuando no de definiciones irrelevantes. Falsas porque ni todos los estudiosos del derecho positivo se dedican a desarrollar estas actividades ni son las únicas que realizan ${ }^{4}$. E irrelevantes porque quienes ofrecen tales definiciones pretenden determinar en qué consisten dichas actividades, no lo que de hecho hacen los estudiosos del derecho. Pero para analizar en qué consisten estas actividades no necesitamos en absoluto un concepto de «ciencia jurídica», ni menos todavía afirmar que es esto lo que hacen los juristas.

2. En segundo lugar, si se trata de una definición que pretende indicar qué es lo que los estudiosos del derecho deben hacer, aquélla resulta injustificada. La razón es sencilla: estaríamos resolviendo un problema práctico a través de una definición. Dicho de otro modo: si lo que pretendemos es orientar la conducta de los estudiosos del derecho positivo - qué deben hacer- es preciso ofrecer razones prácticas, no una definición acerca de la supuesta «naturaleza» del derecho.

Llegados a este punto, lo primero que hay que hacer es preguntarnos para qué queremos una definición de «ciencia jurídica» ${ }^{5}$. Parafraseando a F. COHEN, es posible afirmar que, en relación a la «ciencia jurídica», existen dos preguntas relevantes: en primer lugar, qué hacen los estudiosos del derecho; en segundo lugar, qué deben hacer ${ }^{6}$. Y nada más.

Lo que necesitamos, por tanto, es una definición que no prejuzgue respuesta alguna a estas dos preguntas pero que, al mismo tiempo, sea funcional a tales empresas (describir qué hacen los estudiosos del derecho y/o realizar propuestas sobre qué deben hacer), que no esté fundada en asunciones falsas y que no se aleje demasiado de lo que normalmente entendemos por «ciencia jurídica».

3 Sin embargo, conviene desconfiar de estas pretensiones ontológicas respecto de cualquier definición del concepto de derecho. Si una conclusión podemos obtener del largo debate de los últimos años acerca del concepto de derecho es que cuál sea nuestro mejor concepto de derecho depende, aunque no sea el único criterio, de cuáles sean las pretensiones del marco teórico en el que se incluye.

${ }^{4}$ Para una lista amplia, que no exhaustiva, del conjunto de operaciones desarrolladas por los estudiosos del derecho, vid. CRUZ PARCERO, 2006, y COURTIS, 2006b.

${ }^{5}$ Cuáles son las condiciones de ajuste de la definición de un concepto es materia discutida. Aquí consideraré que la plausibilidad de un concepto depende de las siguientes condiciones: i) no basado en asunciones manifiestamente falsas; ii) funcional para el desarrollo de una teoría; iii) responde a algunas de las intuiciones fundamentales de los hablantes. Sobre este punto, vid. COHEN, 1959: 11 y ss.

${ }^{6}$ «Fundamentalmente, sólo hay dos cuestiones con significado en el campo del derecho. Una es “¿Cómo deciden de hecho los tribunales casos de un determinado tipo?”. La otra es “¿Cómo deberían decidir los tribunales casos de un tipo determinado?". A menos que un problema "jurídico" pueda ser subsumido bajo una de estas formas, no es una cuestión con sentido y cualquier respuesta al mismo tendrá que ser un sinsentido». Cfr. COHEN, 1962: 58 . 
Pues bien, desde este punto de vista, la mejor definición de «ciencia jurídica» de la que disponemos es aquella que simplemente hace referencia a aquello que hacen, o deberían hacer, los estudiosos del derecho positivo. Es decir, el método, la actividad y/o el resultado que ocupa labor de quienes se dedican a la investigación jurídica.

Por supuesto, se trata de una definición bastante ambigua y vaga en sus diferentes acepciones. No obstante, nos dice ya una cosa importante: denota aquello que hacen las personas que se dedican a la investigación jurídica, y no a las actividades de quienes intervienen en procesos a los que el ordenamiento reconoce valor jurídico. Desde luego, jueces, fiscales y abogados también pueden hacer ciencia jurídica, y es posible que los estudiosos del derecho asuman —o deban asumir — el mismo método que aquellos. Pero, más allá de la respuesta a esta última pregunta, es preciso distinguir inicialmente entre lo que hacen los estudiosos del derecho y los operadores jurídicos para no confundir ambas cuestiones. Y parece que el mejor criterio a disposición para distinguir entre estos dos tipos de sujetos es que el ordenamiento no concede valor jurídico a los enunciados de la ciencia jurídica ${ }^{7}$.

Sin embargo, necesitamos delimitar todavía más nuestro concepto de «ciencia jurídica» porque hay muchos tipos de investigación jurídica a los que el ordenamiento no reconoce valor jurídico, pero no todos ellos corresponden a lo que normalmente se entiende por «ciencia jurídica»: la historia del derecho, la antropología jurídica, la informática jurídica, la teoría general del derecho, etc. Una cierta diferencia, no obstante, existe entre estas disciplinas y aquello que normalmente se entiende por «ciencia jurídica». A saber: mientras que las anteriores disciplinas persiguen diferentes objetivos, las diferentes concepciones de la ciencia jurídica pretenden todas ellas determinar cuál es el contenido del derecho. Es decir, establecer si una conducta está permitida, prohibida o es obligatoria en un determinado ordenamiento. Ésta es la pregunta característica a la que trata de responder la ciencia jurídica, y aunque no sea la única, todas las demás son dependientes de ella ${ }^{8}$.

Se trata, por supuesto, de una definición ambigua: bajo el paraguas «método para la determinación del contenido del derecho en procesos a los que el ordenamiento no reconoce valor jurídico» caben muy diferentes tesis acerca de qué hacen o deben hacer los estudiosos del derecho. No obstante, tal definición permite delimitar la actividad de los estudiosos del derecho respecto de otros estudios sobre el derecho y de los operadores jurídicos ${ }^{9}$. Pero, y sobre todo, no presupone (ni introduce subrepticiamente)

7 Esto nos pone frente al problema de si algunos ejemplos excelentes de la ciencia jurídica occidental - como la romana y aquéllas de comentadores y glosadores - deberían o no ser calificadas como casos de ciencia jurídica en la medida en que los respectivos ordenamientos les reconocían valor jurídico. No obstante, y pese a la evidente dificultad, podemos mantener la distinción: en el momento en que el ordenamiento reconoce a estos escritos valor jurídico se convierten en parte del derecho mismo, no en algo que trata sobre el derecho. La ciencia jurídica queda así definida como una propiedad disposicional que podemos predicar de algunos textos según lo dispuesto por el ordenamiento al que se refieren. En este sentido, lo que en un momento determinado puede ser considerado como ciencia jurídica, puede ya no serlo en un momento posterior.

${ }^{8}$ Las teorías generales del derecho positivo - teoría del contrato, del delito, del tributo, etc. - no pretenden calificar directamente conductas. No obstante, dichas teorías pretenden servir, en última instancia, como esquemas conceptuales para la identificación de normas y calificación de conductas.

9 Por supuesto, esto no implica que los estudiosos del derecho no deban colocarse en el punto de vista interno, externo o en el intermedio. Simplemente mi definición de ciencia jurídica no se compromete con ninguna de estas posiciones. 
ninguna tesis acerca de qué es lo que efectivamente hacen ni, menos todavía, sobre qué es lo que deben hacer los estudiosos del derecho positivo.

\subsection{Modelos de ciencia jurídica en sentido amplio}

Una vez que disponemos de un marco conceptual adecuado podemos analizar las diferentes respuestas que se han dado a las preguntas sobre qué hacen y qué deben hacer los estudiosos del derecho.

A lo largo de la historia del pensamiento jurídico se han ofrecido diferentes clasificaciones sobre los tipos de respuestas a estas preguntas (WROBLEWSKI, 1989; JAKAB, 2011; LLEWELLYN, 1953; GuASTINI, 2011: 440 y ss.). Aunque se trataría de una tarea ciertamente útil, no voy a intentar dar cuenta de estas diferentes clasificaciones. Aquí me voy a concentrar en las respuestas a la segunda pregunta: qué deben hacer los estudiosos del derecho.

Para abordar dicha tarea es conveniente introducir dos distinciones entre diferentes respuestas a esta pregunta.

I) La primera de ellas tiene que ver con dos de las más importantes tradiciones del pensamiento jurídico occidental y, más en general, de la filosofía moderna: racionalismo y empirismo. Aquí no es posible delinear con precisión estas dos grandes tradiciones por lo que me limitaré a señalar las dos corrientes en las que han encontrado traducción en el pensamiento jurídico: la que concibe el derecho como norma y aquella que concibe el derecho como hecho ${ }^{10}$.

Dentro de la primera tradición podemos encontrar autores como KELSEN, BOBBIO, BulYgin o el propio HaRT, pero también a otros como AtienZA, NinO, CALSAMIGLia, ZAGREBELSKY, DwORKIN, AARNIO o AlEXY ${ }^{11}$. En el segundo grupo encontramos, sobre todo, a los realistas jurídicos, pero también a algunos de sus precursores como JHERING ${ }^{12}$, HOLMES o POUND, y a algunos de sus herederos como R. POSNER y B. LEITER. Aquí me voy a concentrar en este segundo grupo de autores.

II) La segunda distinción, de origen bobbiano (BOBBIO, 1992), es algo más precisa. Tiene que ver con dos formas en las que podemos interpretar la definición de

10 No se trata de una gran división — por usar la terminología bobbiana- pues no es exhaustiva ni excluyente, al menos en el uso que aquí estoy haciendo de ella. Pese a todo, nos sirve para orientarnos entre las diferentes teorías normativas de la ciencia jurídica: las que consideran que objeto fundamental de los estudiosos del derecho debe ser un conjunto de normas, y quienes consideran que los estudiosos del derecho deben analizar hechos sociales.

11 Aquí sería necesario establecer una distinción entre los diferentes tipos de «normativismo» que suscriben estos autores. Ello porque calificar de normativistas a autores como ATIENZA, ALEXY o DWORKIN, es una afirmación reductiva o poco precisa. Sin embargo, parece posible calificar también estos autores como «normativistas» en un determinado sentido de «normativismo». A saber: para todos ellos la ciencia jurídica (en sentido amplio) debe consistir en usar normas jurídicas para determinar la calificación deóntica de conductas. Por supuesto, estos autores mantienen diferentes concepciones sobre qué son y cuáles son las «normas jurídicas». Pero, en cualquier caso, esto parece constituir una diferencia sustancial respecto a quienes consideran que los estudiosos del derecho deben dedicarse a describir hechos. Agradezco a M. AtIENZA que me señalara esta imprecisión. Para una clasificación de los diferentes modelos de ciencia jurídica en sentido amplio me permito remitir a A. NúÑEZ VAQUERO, 2012.

12 Por supuesto, me refiero al segundo JHERING, el de El fin del derecho (JHERING, 1999), La lucha por el derecho (JHERING, 1993) o Bromas y veras en la ciencia jurídica (JHERING, 1987). 
ciencia jurídica en sentido amplio que he ofrecido antes. Si nos situamos en el campo de las doctrinas acerca de qué deben hacer los estudiosos del derecho, podemos identificar al menos dos respuestas: los estudiosos del derecho deben limitarse a describir el derecho de un determinado ordenamiento, o bien deben dedicarse a orientar las decisiones judiciales, ofreciendo respuestas para los casos difíciles.

Siguiendo esta distinción voy a definir «ciencia jurídica en sentido estricto» como aquellos métodos recomendados por quienes consideran que los estudiosos del derecho deben limitarse a describir el contenido del derecho. Lo que me interesa subrayar es que se trata de doctrinas sobre qué deben hacer los estudiosos del derecho. El hecho de que dichos métodos sean o no realmente descriptivos, o incluso científicos, es una cuestión diferente.

De manera complementaria, voy a definir como doctrinas de la «dogmática jurídica» aquellos métodos recomendados por quienes consideran que los estudiosos del derecho no deben limitarse $-\mathrm{O}$ no deben dedicarse en absoluto ${ }^{13}$ - a describir el contenido del derecho sino que tiene como función principal orientar la conducta judicial para la resolución de casos difíciles. Del mismo modo que con la anterior definición de «ciencia jurídica en sentido estricto», ello no implica que se trate de una disciplina poco rigurosa o basada en las preferencias personales de los estudiosos del derecho. Éstas, simplemente, son cuestiones diferentes que en nada afectan a las definiciones que aquí estoy adoptando de «dogmática jurídica» y «ciencia jurídica en sentido estricto».

\section{MODELOS DE CIENCIA JURÍDICA REALISTA}

Una vez que hemos delineado un concepto de «ciencia jurídica en sentido amplio», y otros dos de «ciencia jurídica en sentido estricto» y de «dogmática jurídica», voy a concentrar mi atención en los diferentes métodos que, desde un punto de vista realista, se han ofrecido para desarrollar una ciencia jurista realista. Por supuesto, no se trata de los únicos métodos que se han propuesto desde la tradición jurídica empirista, pero sí algunos de los más conocidos e interesantes entre quienes conciben el derecho como hecho.

\subsection{Los realismos jurídicos}

Antes de pasar a caracterizar cada uno de estos modelos realistas de ciencia jurídica en sentido estricto es necesario realizar una breve caracterización de qué es lo que une a estas formas de estudiar el derecho: la teoría jurídica realista. Sin embargo, reconstruir las tesis características del realismo jurídico no es en absoluto una tarea sencilla. Por varias razones.

13 Según algunos autores, describir el contenido del derecho sería una pérdida de tiempo porque constituiría una mera repetición de cuanto ya expresado por los enunciados normativos. Se trata de una curiosa, pero no infrecuente, combinación entre formalismo y modelo axiológico o argumentativo de dogmática jurídica. Cfr. Neumann, 1992. 
La primera de ellas es que con el término «realismo jurídico» normalmente hacemos referencia a una larga lista, de contornos no bien definidos, de autores que pueden ser agrupados al menos en cuatro grupos o «escuelas»: los realismos americano, escandinavo, genovés y francés ${ }^{14}$. A esta heterogeneidad de escuelas hay que añadir las tesis de algunos autores que, a buen título ${ }^{15}$, podrían ser incluidos dentro de la tradición realista, como M. D. FARRELL; y otros, como R. POSNER, que rechazan tal denominación pero cuyas propuestas teóricas coinciden sustancialmente con las tesis más significativas de los realistas (POSNER, 2011).

En segundo lugar, más allá de problemas de homogeneidad de tesis de los realismos clásicos —americano, escandinavo, genovés y francés-, también se ha afirmado que aquella realista no sería exactamente una teoría del derecho sino únicamente una teoría de la decisión judicial. Ello porque, según esta tesis, presupondrían el mismo concepto de derecho que el positivismo normativista de tipo excluyente ${ }^{16}$.

En tercer lugar, la tarea resulta complicada también porque la caracterización estándar del realismo jurídico ha sido frecuentemente una descripción distorsionada ${ }^{17}$, cuando no claramente caricaturizada o errónea ${ }^{18}$. Ello en parte se ha debido al tono polémico y claramente exagerado de algunas de las tesis realistas, especialmente de los americanos.

En cuarto lugar, tampoco la negativa de estos autores a calificarse en términos de «escuelas» facilita la tarea. Si bien existen algunos manifiestos acerca de en qué consistiría la ciencia jurídica realista, es discutible en términos históricos qué autores compartían dichas tesis ${ }^{19}$. Además, las polémicas y diferencias entre los propios realistas también han sido notables: LUNDSTEDT fue duramente criticado por ROSS, LLEWELLYN no comparte algunas tesis fundamentales con FRANK, ni GUASTINI y COMANDUCCI sostienen las mismas tesis.

Reconstruir las tesis teóricas fundamentales sostenidas por este grupo de autores no es, por tanto, una tarea sencilla. Una de las posibles estrategias para la reconstrucción consiste en formular una serie de tesis que serían efectivamente sostenidas por todos estos autores.

${ }^{14}$ En este sentido, algunos autores han negado que alguna de estas escuelas pueda ser calificada como realista, mientras que otros han negado que se pueda hablar de «realismo jurídico» y no más bien de diferentes «realismos» que poco tendrían en común. De hecho, se ha llegado a afirmar que entre los diferentes realismos no existen conexiones de relevancia sino un mero fenómeno de homonimia, o incluso que sería conveniente abandonar el adjetivo. Cfr. Friedmann, 1960: 340.

15 A buen título porque existen otros autores que se consideran realistas pero no en el sentido tradicional en la teoría jurídica, sino como realistas meta-físicos de corte iusnaturalista, como J. HeRvaDA. Cfr. HERVADA, 2002.

16 Leiter, 2007. Para la opinión contraria, vid. PatTaro, 1971.

17 J. A. PÉREZ LlEDó da cuenta de algunas de estas lecturas erróneas de las tesis del realismo jurídico americano. Cfr. PÉREZ LLEDó, 2008. Vid. también LeITER, 2007.

18 Por ejemplo, entre las más famosas está aquella que considera que los presupuestos filosóficos y/o epistemológicos del realismo jurídico escandinavo se encuentran en el neo-positivismo lógico. A menos que la tesis sea matizada y limitada a Ross, la afirmación es simplemente falsa. Vid., por ejemplo, MonTORo BaLLESTEROS, 2007: 172.

${ }_{19}$ M. HoRWITZ ha sido uno de los autores que han puesto en entredicho el protagonismo de LLEWELLYN dentro del realismo jurídico, especialmente sobre cuánto representativa de las posiciones de todos los realistas sea su famosa respuesta «Some realism about realism» (LLEWELLYN, 1930-1931). Cfr. HoRWITZ, 2004: 303 y ss. Véase también TAMANAHA, 2009. 
Sin embargo, buscar el mínimo común denominador que uniría a todos los realistas no resulta demasiado interesante. Por dos razones: por un lado, porque es una tarea que ya ha sido afrontada por otros (CASTIGNONE, 1995; TARELLO, 1974; MARTIN, 1997); por el otro, porque resultaría poco útil para mis fines dado que mis pretensiones aquí no son de carácter filogenético. Es decir, no sostendré que cada uno de los autores antes mencionados suscriban todas y cada una de las tesis que me parecen características del realismo jurídico. Lo que presentaré es la que considero la mejor reconstrucción de las tesis del realismo jurídico, y no defenderé que cada una de ellas pueda ser atribuida a cada uno de los autores que pueden ser incluidos dentro de la tradición realista.

Con las anteriores cautelas es posible identificar las tesis más características de las diferentes versiones del realismo jurídico:

i) Común oposición tanto a las teorías del derecho iusnaturalistas y normativistas como a los modelos de ciencia jurídica formalista y axiológica.

ii) Si bien no comparten un conjunto homogéneo de tesis epistemológicas ni ontológicas, las tesis que presuponen estos autores descienden claramente de un único tronco filosófico común: el empirismo filosófico ${ }^{20}$.

iii) Una teoría escéptica de la decisión judicial en general, y de la interpretación en particular.

iv) Crítica del método para la elaboración y uso de los conceptos jurídicos dogmáticos y teóricos.

v) Rechazo a la hora de definir el concepto del derecho, acompañado de algunas manifestaciones provocadoras acerca del concepto predictivo de derecho.

vi) Una doctrina de la ciencia jurídica en sentido estricto, es decir, la tesis según la cual los estudiosos del derecho positivo deben desarrollar, en general, una tarea meramente descriptiva y, en particular, de carácter predictivo.

vii) Tesis de la indeterminación del derecho.

Me voy a detener con mayor detalle en dos de estas tesis, comunes a la mayoría de estos autores, que - conjuntamente- constituyen el punto sobre el que se basan los modelos de ciencia jurídica que presentaré a continuación: A) el carácter marcadamente crítico de estos movimientos; B) la tesis de la indeterminación del derecho.

A) Como es bien sabido, los diferentes realismos surgen como movimientos de reacción frente a otros modelos de ciencia jurídica (en sentido amplio) y/o contra otras teorías (o filosofías) generales del derecho. Se trata de objetivos de crítica diferentes: el realismo escandinavo surge contra el idealismo borstromiano, el americano como reacción al formalismo langdelliano y el realismo genovés como reacción al positivismo formalista y al neoconstitucionalismo.

No obstante, es posible identificar al menos dos puntos comunes en las críticas de estos autores: una crítica de carácter epistemológico (u ontológico) y otra de carácter metodológico. Si bien ambas críticas están íntimamente relacionadas, se trata de cuestiones que conviene presentar separadamente.

20 Para una reconstrucción de las tesis epistemológicas de los realistas escandinavos en los términos del naturalismo filosófico, vid. SPAAK, 2009. 
A.1) Crítica epistemológica (u ontológica). Esta primera crítica se apoya en una aproximación radicalmente empirista, y puede ser interpretada tanto en una versión ontológica (acerca de lo que existe) como en una versión epistemológica (acerca de cómo lo podemos conocer). Existen diferentes tipos de empirismo, y sería bastante imprudente afirmar que todos de estos autores sostienen el mismo. Sobre lo que, sin embargo, puede encontrarse homogeneidad es en la traducción en campo jurídico de esta tesis: todo discurso que no tenga por objeto entidades del mundo sensible, debe ser expulsado del ámbito del estudio científico del derecho ${ }^{21}$ o, cuando menos, debe ser empleado con extrema cautela ${ }^{22}$.

Según esta crítica, el positivismo normativista constituiría una continuación del iunaturalismo por otros medios ${ }^{23} \mathrm{y}$, al igual que este último, en la descripción del derecho haría referencia a entidades de origen mágico-religioso de dudosa existencia tales como «culpa», «validez» u «obligatoriedad». El discurso jurídico del positivismo normativista se convierte así en un discurso consistente en un conjunto de proposiciones incontrolables pues no tienen como objeto realidad empírica alguna.

A.2) Crítica metodológica. Según la crítica metodológica, más allá de cuáles sean los problemas relativos a la existencia de tales entidades, el problema sería que el método de los juristas genera indeterminación. Es decir, no se trata tanto de que no exista nada «ahí fuera» como la validez o la culpa, sino que el conjunto de técnicas o reglas de transformación admitidas en el discurso o método jurídico permiten llegar, justificadamente, a conclusiones incompatibles. Esto nos conduce a la segunda tesis realista de la que me ocuparé.

B) La segunda tesis importante sobre la que se apoyan los diferentes modelos de ciencia jurídica (en sentido estricto) realista es la tesis de la indeterminación del derecho. Por tesis de la indeterminación del derecho podemos entender cosas diferentes ${ }^{24}$ : la tesis de la indeterminación racional del derecho y la tesis de la indeterminación causal o empírica del derecho.

i) Por tesis de la indeterminación racional es posible entender la tesis según la cual a partir del mismo conjunto de enunciados normativos y de los diferentes de instrumentos metodológicos vigentes en la comunidad jurídica es posible justificar diferentes respuestas jurídicas para un mismo caso, genérico o individual. Es decir, es posible ofrecer calificaciones jurídicas incompatibles para la misma conducta o tipo de conducta de manera justificada.

Existen diferentes causas de indeterminación racional del derecho pero aquí me voy a limitar a señalar una para aclarar su alcance: la tesis de la ambigüedad de los enunciados normativos. Según la teoría escéptica de la interpretación, a partir de un mismo enunciado normativo (o conjunto de enunciados normativos) es posible derivar diferentes interpretaciones-producto. Ello debido a que interpretar no es otra cosa

\footnotetext{
21 «Toda palabra que no tenga provisión de fondos en moneda de hechos [...] es declarada en bancarrota». Cfr. CoHen, 1962: 53.

22 Vid. Ross, 1976, Olivecrona, 1980: 179 y ss., y Olivecrona, 2010.

${ }^{23}$ Han sido varios los autores que han llamado la atención sobre la continuidad de método entre iusnaturalismo y positivismo normativista. Vid., por ejemplo, BOBBIO, 1996: 36 y ss.

${ }^{24}$ Aquí estoy siguiendo sustancialmente a LeITER. Vid. LeITER, 1995.
} 
que aplicar reglas lingüísticas (lenguaje natural más lenguaje jurídico) y, dado que en nuestras comunidades jurídicas están presentes una variedad de criterios interpretativos y no disponemos de meta-criterios jurídicos últimos que nos indiquen cuál es el criterio que debemos aplicar, entonces del mismo enunciado o conjunto de enunciados normativos podemos derivar diferentes normas. De este modo, resulta posible ofrecer diferentes respuestas jurídicas incompatibles pero igualmente justificadas para un mismo caso.

Contra esta versión de la tesis de la indeterminación racional del derecho normalmente se ha argüido que nadie duda de cuál es el significado o la norma expresada por algunos enunciados normativos. Sin embargo, tal crítica se basa en un malentendido porque la tesis de la indeterminación del derecho, en su versión de la ambigüedad de los enunciados normativos, no afirma que se produzca un desacuerdo acerca de cada una de las normas expresadas por cada enunciado normativo. Esta tesis sería sencillamente falsa.

Antes bien, lo que afirma la tesis de la ambigüedad de los enunciados normativos es que es posible —más allá de que exista un acuerdo acerca del significado expresado por un enunciado normativo- derivar justificadamente a partir del mismo enunciado o conjunto de enunciados normativos otra norma que califica la misma conducta de manera diferente. La tesis de la ambigüedad de los enunciados normativos no se refiere al hecho de que existan desacuerdos interpretativos, sino al hecho de que existen diferentes criterios interpretativos vigentes en la comunidad a partir de los cuales se puede atribuir, justificadamente, un significado diferente a los enunciados normativos ${ }^{25}$. Si bien ello no se produce en todos los casos, existe un no despreciable conjunto de enunciados que pueden ser interpretados de maneras incompatibles.

ii) Existe, en segundo lugar, un sentido diferente en el que podemos afirmar que el derecho está indeterminado: la tesis de la indeterminación empírica o causal derecho. Según esta última tesis, si el derecho está indeterminado racionalmente —es decir, es posible justificar más de una solución para el caso particular- entonces la suma de enunciados y métodos jurídicos tampoco constituyen un elemento suficiente para la explicación de las decisiones judiciales. De este modo, si el conjunto de enunciados normativos permiten justificar diferentes respuestas jurídicas, entonces el análisis de las razones jurídicas no constituye base suficiente para realizar predicciones ya que no permiten explicar por qué los jueces optan por una decisión en detrimento de otras ${ }^{26}$.

${ }^{25}$ Lo que sí haría falsa dicha tesis sería que los diferentes criterios interpretativos condujeran siempre a los mismos resultados interpretativos, como J. J. MORESO ha señalado en diferentes ocasiones. Cabe poca duda de que esta situación se produce en muchas ocasiones, pero es más que discutible que produzca.

${ }^{26}$ Puede darse el caso de que sean razones jurídicas las que expliquen al menos algunas decisiones judiciales, aun cuando el derecho esté racionalmente indeterminado. Ello sucederá toda vez que el juez seleccione una de las razones jurídicas en conflicto, y la utilice como razón última y concluyente. En este caso, el derecho seguiría estando igualmente indeterminado porque no hay ningún meta-criterio jurídico último que indique que debe ser la razón jurídica seleccionada por el juez la que funcione como razón concluyente. Sin embargo, en este caso sería una razón jurídica la que explicará la decisión.

No es por tanto suficiente analizar las razones jurídicas para predecir las decisiones judiciales aunque el tribunal haya usado una razón jurídica como una razón concluyente. Por el contrario, es necesario observar cuál ha sido la razón jurídica que, de hecho, el juez adopta como razón última y concluyente. 
Estando así las cosas, enunciados y métodos jurídicos no constituyen elemento suficiente ni para prever las decisiones judiciales ni para tomar decisiones jurídicas. Ello, en ambos casos, debido a que a partir de los mismos enunciados jurídicos es posible justificar decisiones incompatibles.

\subsection{Modelos realistas de ciencia jurídica en sentido estricto}

Una vez que disponemos de un marco conceptual adecuado y hemos presentado las características básicas de la teoría jurídica realista, podemos analizar algunos de los diferentes modelos de ciencia jurídica (en sentido estricto) realista. Se trata de «modelos», no de un único modelo de ciencia jurídica realista, es decir, de una pluralidad de métodos para realizar predicciones acerca de las futuras decisiones judiciales.

Antes de pasar a analizar tales métodos es necesario, no obstante, realizar una consideración previa en relación al objetivo o función de la ciencia jurídica realista.

No cabe duda de que la mayoría de los realistas insistieron sobre la necesidad de abordar el estudio del derecho mediante una metodología científica que tomar como objeto de estudio hechos. Ahora bien, lo que no hicieron todos los realistas, y desde luego no todos en la misma manera, es afirmar que los estudiosos del derecho deben realizar predicciones acerca de las futuras decisiones judiciales.

Algunos de ellos pensaron, como HUTCHENSON o FRANK ${ }^{27}$, que una tal empresa estaba destinada al fracaso porque las decisiones judiciales respondían a factores demasiado particulares (idiosyncratic wing). Otros han afirmado, como recientemente R. GUASTINI (GUASTINI, 2011: 444 y ss.), que la ciencia jurídica realista consiste sobre todo en la descripción de decisiones judiciales. Y en este mismo sentido, otros realistas - como BARBERIS- defienden que los estudiosos del derecho deben limitarse a indicar las fuentes de indeterminación en el razonamiento jurídico, no a realizar predicciones.

Sin embargo, no parece una buena idea reconstruir de este modo el modelo realista de ciencia jurídica porque genera algunos problemas. En primer lugar, porque si la ciencia jurídica realista debe dedicarse a describir decisiones pasadas ésta sería — como dijo en su día NiNO (NiNO, 2003: 53 y ss.) — una tarea que ya cumplen satisfactoriamente las revistas de actualidad jurisprudencial.

En segundo lugar, la mayoría de los realistas no afirman únicamente la tesis de la indeterminación racional del derecho, sino que ofrecen explicaciones alternativas acerca de cuáles son las razones a las que recurren los jueces a la hora de resolver las controversias ${ }^{28}$. El problema es que si nos comprometemos — como parece que hacen

Este argumento parece además suficiente para rechazar la tesis de LEITER según la cual toda vez que el derecho está racionalmente indeterminado, los jueces recurren necesariamente a razones extra-jurídicas para decidir las controversias jurídicas. Así pues, y en contra de lo que cree LEITER, es posible que el derecho esté racionalmente indeterminado y que sean razones jurídicas las que expliquen la decisión. Cfr. LEITER, 2007: $43-45$.

27 No obstante, hasta el mismo J. FrANK consideraba que era posible realizar predicciones cuando los hechos del caso no son controvertidos. vid. Frank, 1949, y FranK, 2001: 80-81. Vid. también HuTCHENSON, 1929.

28 Desde luego, siempre es posible refutar una teoría sin ofrecer una explicación alternativa, pero no es esto lo que hacen la mayoría de los realistas sino que ofrecen explicaciones alternativas sobre cómo deciden los jueces. 
los realistas - con una epistemología empirista, entonces parece plausible afirmar que una explicación satisfactoria acerca de cómo deciden los jueces debe constituir base suficiente para realizar predicciones acerca de cómo efectivamente decidirán. Es decir, una explicación satisfactoria debe identificar los factores causalmente suficientes para que un juez opte por una decisión en detrimento de otras decisiones posibles. En caso contrario, no dispondríamos — desde el punto de vista empirista — de ninguna razón para considerar la teoría realista de la decisión mejor que cualquier otra. Por tanto, la ciencia jurídica realista está comprometida con algún tipo de predictivismo por razones teóricas.

Con esta premisa podemos afrontar ahora el análisis de algunos métodos para realizar predicciones acerca de cómo decidirán los jueces en el futuro.

1) Ross. El primer modelo de ciencia jurídica realista, aunque no sea temporalmente el primero, es sin duda el más sencillo y el que más difusión ha tenido en la cultura jurídica europeo-continental. Me refiero al modelo de ciencia jurídica propuesto por A. Ross ${ }^{29}$.

Como es bien sabido, el modelo de ciencia jurídica de Ross intenta combinar dos modelos de ciencia jurídica anteriormente formulados por Holmes y OliveCRONA: el primero de ellos, llamado «conductista», identifica el objeto de estudio de la ciencia jurídica con las decisiones judiciales; el segundo, llamado «psicologicista», identifica el derecho existente con los sentimientos de obligatoriedad de la comunidad jurídica en general, y de los jueces en particular (Ross, 1997: 99 y ss.).

Frente a estos modelos, Ross redefine el objeto de estudio de la ciencia jurídica (derecho vigente) como el conjunto de normas sentidas como obligatorias (válidas) y aplicadas por los jueces. De este modo, se evita reducir el derecho existente al conjunto de normas aplicadas por los jueces, por un lado, y se evita recurrir a - lo que hoy llamaríamos- los estados mentales de los jueces para determinar el derecho válido.

Cuál sea el derecho vigente dependerá, por tanto, de dos factores: en primer lugar, de la concreta doctrina de las fuentes del derecho de los jueces, es decir, del conjunto de creencias normativas sostenidas por los jueces acerca de qué debe contar como derecho y, en segundo lugar, de su efectivo comportamiento (Ross, 1997: 135 y ss.).

Para entender la teoría normativa de la ciencia jurídica de Ross lo primero que es necesario hacer es aclarar cuál es la función de la ciencia jurídica. Pues bien, es importante señalar que para Ross tarea de la ciencia jurídica no es realizar predicciones acerca de las concretas decisiones judiciales sino únicamente acerca de las normas que serán aplicadas por aquellos. Tal tarea —realizar predicciones acerca de las concretas decisiones judiciales - sería función de la sociología del derecho, no de la ciencia jurídica realista (Ross, 1997: 42 y ss.).

Sin embargo, cuál es el objeto de predicción para Ross no es del todo claro. En primer lugar, parece que para Ross objeto de predicción no serían las normas en sentido estricto sino los enunciados normativos (directivas o disposiciones normativas). Ahora bien, si admitimos la tesis de la indeterminación racional del derecho en su vertiente de la ambigüedad de los enunciados interpretativos, entonces no tiene mucho interés

${ }^{29}$ Aclaro que me voy a referir exclusivamente al Ross de Sobre el derecho y la justicia (Ross, 1997). 
saber qué disposición utilizará un juez para justificar su decisión porque a partir del mismo enunciado normativo podrá justificar diferentes decisiones del caso particular.

En segundo lugar, y admitiendo que objeto de predicción son normas (y no enunciados), Ross parece afirmar que objeto de predicción son las normas tenidas en cuenta por los jueces, y no únicamente la que funciona como premisa mayor del silogismo judicial ${ }^{30}$. Sin embargo, esto tampoco resulta muy interesante porque no constituye un elemento suficiente para prever cómo decidirán los jueces las futuras controversias.

No son estos los únicos problemas que debe afrontar la ciencia jurídica rossiana. Un segundo grupo de problemas hace referencia a que la metodología propuesta por Ross para realizar predicciones termina siendo indistinguible del conductivismo. Ello debido a que Ross realiza una doble reducción del objeto de estudio de la ciencia jurídica realista.

En primer lugar, Ross reduce el análisis de la ideología de las fuentes a aquello que los jueces afirman en sus decisiones judiciales. Sin embargo, resulta poco plausible afirmar que las decisiones judiciales reflejen el contenido de la ideología de las fuentes de los jueces, precisamente porque los jueces normalmente no hacen explícitas las razones que realmente les han llevado a optar por una decisión. Por ello LLEWELLYN insistió en que era necesario prestar atención a lo que hacen, y no solo a lo que dicen, los jueces (LLEWELLYN, 1931: 1237).

En segundo lugar, cuando Ross nos propone un método para realizar predicciones judiciales se limita a conjeturar que casos similares serán decididos de manera similar. En este sentido, cuando Ross intenta traducir su teoría de la decisión judicial en un método que permita realizar predicciones, el factor principal que determinaría — según el propio Ross - las decisiones judiciales (la ideología de las fuentes) desaparece. En este sentido, el modelo de ciencia jurídica de Ross termina haciéndose indistinguible del conductivismo holmesiano pues son sólo normas (o las disposiciones) aplicadas por los jueces las que constituyen objeto de la ciencia jurídica realista.

El resultado es una ciencia jurídica que únicamente sirve para prever cómo decidirán los jueces cuando aquellos decidan los casos similares de la misma manera. Si bien Ross ofrece una teoría de la decisión judicial en la que es la ideología de las fuentes la que determina las decisiones judiciales, tal tesis no encuentra traducción en un método para realizar predicciones. En conclusión: este modelo de ciencia jurídica parece demasiado simple.

2) Situation-types y rationale. El segundo modelo de ciencia jurídica realista que deseo presentar es aquél del situation-type, característico del realismo jurídico norteamericano. Aquí no analizaré los diferentes modelos de ciencia jurídica (en sentido estricto) presentados por los realistas americanos ${ }^{31}$, sino que deseo concentrarme en una forma de realizar predicciones sobre la que no se ha llamado suficientemente la atención. En concreto, voy a exponer, en primer lugar, la forma que propuso $\mathrm{H}$. OLIPHANT como medio para dotar nuevamente de contenido a la regla del stare decisis

30 BuLYGIN ha señalado que el objeto de predicción no serían en Ross exactamente las normas aplicadas por los jueces, sino todas aquellas que son tenidas en cuenta a la hora de resolver la controversia jurídica. Vid. BuLYGin, 1991b. Vid. también NiNO, 2003: 51 y ss.; JORI, 1976, 157 y ss.; FARRELL, 1972.

31 Para una síntesis de estas tesis, vid. Martin, 1997; Summers, 1982; Rumble, 1968. 
y, en segundo, la manera en la que se trató de reconfigurar las categorías tradicionales del common law por parte de autores como L. GREEN. A partir de ambas nociones extrapolaré un modelo predictivista de ciencia jurídica (en sentido estricto).

En el ámbito de la discusión del proyecto del Restatement of Law, H. OLIPHANT criticó el uso que, desde hacía varias décadas, se venía haciendo de los precedentes judiciales en Estados Unidos (Oliphant, 1923). Según OliPHANT, los precedentes -que habían nacido a partir de los pleas y habían generado los writs ingleses- habían sido objeto de operaciones conceptuales que permitían que decisiones contradictorias se presentaran como decisiones justificadas con base en el mismo precedente.

No se trata únicamente de que se dé una multiplicidad de precedentes que permiten decidir el mismo caso de maneras incompatibles, pero justificadas, con base en cada uno de ellos. El problema más grave es que un mismo precedente era utilizado para justificar decisiones incompatibles de casos similares. Si esto es posible, según OLIPHANT, es porque en realidad no es tan sencillo establecer cuál ha sido la regla aplicada en el precedente. Las dificultades para determinar qué norma es la que ha funcionado como premisa mayor en un razonamiento judicial son fundamentalmente tres:

i) Problemas relativos a la interpretación de enunciados normativos ${ }^{32}$.

ii) Distinguir entre obiter dicta y ratio decidendi ${ }^{33}$.

iii) El problema de la inducción, es decir, la posibilidad de identificar un infinito número de normas que justifican la misma decisión para el mismo caso de hecho.

Aquí me voy a centrar exclusivamente en el último problema. Según OLIPHANT, el problema fundamental para encontrar qué regla han aplicado los jueces es que existen infinitas normas con un grado mayor o menor de generalidad que permiten justificar la misma decisión para los mismos hechos ${ }^{34}$. Pero, si así están las cosas, el mismo precedente podría ser utilizado para justificar decisiones incompatibles para el mismo caso, añadiendo o quitando propiedades del antecedente de la norma que supuestamente habría aplicado el juez.

Por esta razón la estrategia predictivista de algunos realistas americanos pasa por rodear la idea de norma: en lugar de intentar determinar la ratio decidendi ${ }^{35}$-la norma aplicada en la decisión judicial- lo que se pretende es establecer el rationale ${ }^{36}$ de tal decisión. Esto es, no qué norma ha aplicado el tribunal en su decisión, sino cuáles son los efectos que provoca la decisión: qué cambios produce la decisión en el mundo político, social o económico.

32 Sobre estos problemas, vid. ChIASSONI, 1999. Pero también, Llewellyn, 1950.

33 Sería posible pensar que este problema no es independiente respecto del primero, pero conviene descartar esta idea porque es posible que no tengamos dudas acerca del significado de los enunciados que forman el dispositivo de la sentencia pero que el juez no haya dejado claro cuál es la norma que ha aplicado.

34 Es preciso señalar que este problema, aunque similar, no es el mismo que el del escepticismo a là KRIPKE. En efecto, fueron pocos los realistas que dudaron de la existencia de las normas. Lo que, por el contrario, pone en duda el escepticismo de KRIPKE es la existencia misma de las reglas. No obstante, desde un punto de vista radicalmente empirista, se podrían hacer colapsar ambos problemas.

${ }_{3}$ Para un análisis de los diferentes significados de ratio decidendi, vid. la voz de R. SHINER en la enciclopedia de la IVR (SHINER, 2010).

36 Para una presentación del concepto de rationale, vid. TARELLO, 1962: 208 y ss. 
La segunda y complementaria estrategia ideada en el realismo americano ${ }^{37}$ para afrontar la predicción de decisiones judiciales consiste en — prescindiendo de las categorías tradicionales del common law - asociar tipos de casos individuales (y no casos genéricos descritos en los antecedentes de enunciados normativos) a los efectos que provocan las decisiones de tales casos particulares. De este modo, estos autores pretendieron sistematizar el derecho con base en rígidas y detalladas descripciones de tipos de casos individuales (situation-type), a la que se asocian tipos de decisiones clasificadas según las consecuencias que generaban ${ }^{38}$.

No acaba aquí, no obstante, la tarea de la ciencia jurídica realista. A continuación es necesario revelar si, efectivamente, se dan regularidades en el comportamiento de los jueces o si, por el contrario, la práctica es discordante. Es decir, en primer lugar, se asocian un tipo de casos individuales con las consecuencias que las decisiones judiciales han producido y, a continuación, se comprueba cuántos jueces reaccionan de la misma manera (asocian las mismas consecuencias) ante hechos similares.

No es éste el lugar indicado para analizar las concretas tesis sobre qué factores determinan el derecho según cada realista americano en los diferentes ámbitos jurídicos. Lo que es necesario señalar es que, con carácter general, los realistas americanos moderados ${ }^{39}$ sugirieron dos tesis sobre el comportamiento judicial:

a) Los jueces suelen tener en cuenta las consecuencias socio-económicas de las decisiones que toman.

b) Los jueces normalmente tienden a adaptar su propia conducta a la de sus colegas.

Tal teoría de la decisión judicial nos devuelve un panorama más rico e interesante respecto a aquél de Ross. Sin embargo, el método de los situation-types y rationale de decisiones judiciales enfrenta algunos problemas similares al rossiano. En primer lugar, y del mismo modo que en Ross, este método nos dice simplemente que casos similares seguirán siendo decididos de igual modo. El problema, o el problema interesante, es identificar cuáles son los factores causalmente suficientes que llevan a un juez a preferir una decisión jurídica en detrimento de otras.

Desde luego, esto puede conducir a un regreso al infinito pues siempre es posible preguntarse acerca de las causas últimas que determinan las decisiones judiciales. No obstante, disponemos de un criterio para frenar este regreso al infinito: la capacidad

37 El ejemplo más famoso es el de L. GREEN, un civilista estadounidense quien en un conocido manual resistematizó el derecho estadounidense de daños (torts) prescindiendo de las categorías dogmáticas tradicionales del common law (negligence, intentional torts, etc.), sustituyéndolas por conceptos mucho más particulares y rígidos, construidos a partir de los hechos de casos particulares (como por ejemplo, daños médicos o accidentes de tráfico). Es decir, en lugar de partir de los antecedentes de las normas o de los conceptos dogmáticos del common law, GREEN parte de descripciones muy detalladas y rígidas construidas con base en tipos de casos particulares. GREEN, 1927. Vid. también Douglas, 1929, y ARNOLD, 1930. Para un análisis de los modelos de predicción creados por F. ROdell, Llewellyn, Cohen, Oliphant y MoOre, vid. Rumble, 1968: 142 y ss.

38 Aquí se da claramente un problema a la hora de determinar cuáles son las consecuencias relevantes. Lo que en cualquier caso es importante subrayar es que el interés de estos realistas no se dirige tanto a las consecuencias jurídicas como a las políticas, sociales y económicas. Cfr. TARELLO, 1962: 138 y ss.

39 Estos realistas serían «moderados» en cuanto consideran que los factores que determinan las decisiones judiciales son generales (compartidos por gran parte de los jueces) y estables (cambian, pero no demasiado deprisa). Bajo estas condiciones, sería posible realizar predicciones acerca de las futuras decisiones judiciales. Vid. Oliphant y Hewitt, 1929; Llewellyn, 1931b; Tarello, 1962: 206. 
predictiva. En este sentido, es posible considerar como satisfactoria una explicación en la medida en que aquélla nos sirva para realizar predicciones con un elevado margen de acierto. El problema es precisamente que este método no ha mostrado una capacidad de predicción demasiado elevada.

El segundo problema es que este modo de realizar predicciones parece presuponer que cuestiones tales como la validez o la aplicabilidad de las normas son completamente indecidibles. Es decir, como si presupusieran que el derecho está indeterminado racionalmente de manera radical, como si nada se pudiera decir acerca de las razones jurídicas ${ }^{40}$, o como si los jueces decidieran normalmente más allá del conjunto de respuestas posibles que se pueden justificar con base en el ordenamiento.

Sin embargo, sabemos que dicha asunción es falsa para la mayoría de los casos: por un lado, porque los enunciados normativos permiten normalmente justificar una variedad de decisiones pero no cualquier decisión y, por el otro, aunque los jueces puedan superar (y de hecho en ocasiones lo hagan) tal marco de respuestas disponibles, normalmente no lo hacen. Y parece que dicha información —las respuestas jurídicamente posibles y la identificación de los lugares de indeterminación del derecho- constituye una información relevante a la hora de realizar predicciones pero que no es utilizada por este método.

3) TARELLO. El tercer modelo de ciencia jurídica es el denominado de forma polémica por G. TARELLO «sociología en el derecho» (TARELlO, 1988: 411). Pese al nombre que el propio TARELLO le otorga — «sociología en el derecho»— podemos considerarlo como el modelo de ciencia jurídica propuesto por el autor ${ }^{41}$.

Lo primero que es preciso hacer es contextualizar la propuesta metodológica del autor. TARELLO expuso su teoría normativa de la ciencia jurídica en el ámbito del debate del primer número de la revista Sociologia del Diritto, que se presenta como una discusión acerca de qué deber ser y cómo debe desarrollarse la sociología del derecho.

Pues bien, sus objetivos son claros al respecto y TARELLO toma rápidamente distancias respecto de la sociología del derecho de los sociólogos ${ }^{42}$, rechazando la plausibilidad de una sociología del derecho desde el punto de vista externo (entendido en sentido hartiano). En particular, son tres las orientaciones de sociología del derecho que TARELLO rechaza:

a) En primer lugar, aquella sociología que no toma como objeto de estudio a quienes usan las normas sino cómo se desarrolla el derecho en la sociedad, y que termina siendo un comentario más o menos crítico de las ideologías dogmáticas.

40 Aquí no estoy sosteniendo que los realistas americanos afirmaran que el derecho está radicalmente indeterminado. Se trataría de una tesis simplemente falsa. Ahora bien, este método para realizar predicciones parece presuponer una tesis de la indeterminación radical para los casos que son objeto de predicción, no tomando en cuenta el rango de respuestas justificadas ni las ideologías normativas jurídicas a las que recurren los jueces para elegir una respuesta en detrimento de las otras respuestas jurídicamente posibles.

${ }^{41}$ Ello precisamente porque el propio autor se encarga de calificarlo como «ciencia jurídica». Cfr. TARELLO, 1988: 411.

42 Señala PÉREz Lledó que se podría equiparar la distinción entre scientist y prudents propia del realismo americano, y aquélla entre sociología del derecho y sociología en el derecho que realizaron por su parte TREVES y TARello. Vid. PÉrez Lledó, 2008: 191, n. 114. 
b) En segundo lugar, la sociología que pretende distinguir el derecho de otros fenómenos sociales y que termina siendo una duplicación de las teorías generales del derecho.

c) Finalmente, las sociologías particulares que efectivamente toman como objeto de estudio los operadores jurídicos pero en cuantos miembros de una clase profesional, no como intérpretes y administradores de normas y disposiciones jurídicas.

¿En qué consiste pues este modelo normativo de ciencia jurídica ${ }^{43}$ ? Su sociología en el derecho constituye un intento de explicación de las decisiones judiciales a través del conjunto de doctrinas jurídicas que permiten justificar la elección de una decisión jurídica en detrimento de otras. Es decir, partiendo de la tesis de la indeterminación del derecho, TARELLO busca cuáles han sido las doctrinas —en el ejemplo que TARELLO propone, la teoría general del acto administrativo- que permiten justificar un tipo de decisión.

Sin embargo, TARELLO intenta ir más allá de las razones doctrinales que justificarían cada una de las posibles decisiones jurídicamente posibles. Para TARELLO, cuál sea el resultado de un proceso judicial particular no depende en última instancia de la plausibilidad teórica o ético-normativa de las posiciones en discusión, sino de factores sociales tales como la conveniencia económica: «Nuestro hipotético jurista [...] nos informará de que, en nuestro sistema político, el propietario de terrenos boscosos con vinculación de uso que deseen construir o cambiar el tipo de uso del suelo, deben simplemente hacer quemar el bosque y, una vez destruido, contratar los servicios de un buen administrativista» (TARELLO, 1988: 412).

No obstante, ello no implica que la búsqueda de las zonas de indeterminación del derecho sea irrelevante. Identificar cuáles son las fuentes de indeterminación del derecho y las doctrinas jurídicas dominantes permite establecer el rango de respuestas jurídicamente posibles y probables. Sólo una vez que hayamos identificado la concreta fuente de indeterminación será posible realizar hipótesis plausibles acerca de cuáles son los factores que determinan las decisiones judiciales.

Este modelo de ciencia jurídica realista enfrenta, no obstante, dos problemas. El primero de ellos tiene que ver con las condiciones de verdad de los enunciados que describen la cultura jurídica, y la relación entre sostener una determinada teoría dogmática y un determinado tipo de decisiones. Ello porque, al menos según algunos realistas, las propias teorías dogmáticas - teoría general del delito, del tributo, del acto administrativo, etc. - se encuentran infradeterminadas, sirviendo para justificar decisiones judiciales incompatibles.

El segundo problema es que todavía no sabemos, ni TARELLO ofrece indicaciones en este sentido, cómo utilizar este tipo de conocimiento para realizar predicciones acerca de cómo decidirán los jueces las futuras controversias. Si bien la sociología tarelliana sirve para aumentar nuestro conocimiento acerca de cómo deciden los jueces,

43 «Vorrei sprimere la mia simpatia per, e la quantità delle mie aspetattive da, alcune ricerche sociologiche che vanno compiendosi nell' ambito della giurisprudenza (scienza giuridica) o meglio di una parte di quest'ultima». Cfr. TARELLO, 1988: 409. TARELLO presenta su modelo no sólo en términos normativos sino también descriptivos. Es decir, según el autor, este tipo de estudios empíricos sobre el derecho se estaban realizando en los años setenta en Italia. Sin embargo, TARELLO no cita ningún estudio. 
aquélla no se traduce —al menos no inmediatamente — en un método para que los estudiosos del derecho realicen predicciones sobre las futuras decisiones judiciales ${ }^{44}$.

4) New Legal Realism. El último modelo de ciencia jurídica realista es el del New Legal Realism. Quien conozca la literatura estadounidense sobre predicción de decisiones judiciales hará bien en preguntarse qué tiene de «new» este tipo de realismo porque desde hace ya varias décadas son muchos los sociólogos y estudiosos de ciencia política que realizan estudios empíricos sobre el derecho. Por ello, antes de pasar a analizar algunas de sus tesis, es necesario realizar una breve caracterización general de este grupo de autores.

Pues bien, la primera característica relevante que une a estos autores es que no son estudiosos de ciencia política o sociólogos sino estudiosos de derecho positivo: profesores de materias jurídico-positivas. En este sentido parece que, pese a la cita inicial del texto, se está gestando otra oleada de autores que, en mayor o menor medida, se identifican con uno de los movimientos clásicos del realismo jurídico.

La segunda característica es que, si bien se reconocen en algún sentido en el realismo jurídico, aquello que parece haberles llevado a adoptar una perspectiva y método empiristas ha sido el relativo éxito de los estudios sobre Law and Politics a la hora de realizar predicciones. Es precisamente el relativo éxito de autores como SPAETH y SEGAL a la hora de predecir las decisiones de la Corte Suprema de los Estados Unidos (74 por 100), lo que ha hecho que autores como C. SunSTEIN o F. Cross hayan decidido adoptar un modelo realista de ciencia jurídica.

La tercera característica que es importante señalar es que - aunque se trata de un movimiento extremadamente heterogéneo en el que conviven aproximaciones de tipo empirista con otras de carácter más «filosófico»—la mayoría de estos autores sostienen la relevancia de sus tesis descriptivas a la hora de elaborar doctrinas normativas acerca de cómo debe ser el derecho. Retomando las palabras de LLEWELLYN ${ }^{45}$, mantienen la tesis de la separación entre Ser y Deber Ser de manera temporal, ya que el Ser es relevante a la hora de determinar el Deber Ser.

Sin embargo, del mismo modo que el relativo éxito de los politólogos ha generado un renovado interés por los estudios empíricos sobre el derecho, el New Legal Realism surge, en alguna medida, como movimiento de reacción a lo que es considerado el reduccionismo llevado a cabo por el attitudinal model, cuyos más conocidos defensores son los ya mencionados SPAETH y SEGAL (pero también LEITER). En concreto, tal reduccionismo consistiría en afirmar que las razones jurídicas no determinan, o no limitan en algún sentido, las decisiones judiciales.

44 La sociología en el derecho de TARELLO presupone, o se sobrepone con, la teoría general del derecho, la filosofía política descriptiva y la historia del pensamiento jurídico, y se dedica a realizar estudios particulares sobre cómo actúan los operadores jurídicos en ámbitos bien delimitados del derecho. Por otro lado, el hecho de que TARELLO afirme que se trata de estudios particulares, sobre concretas y delimitadas áreas del derecho positivo no parece en absoluto gratuito, y parece querer cerrar las puertas a afirmaciones de carácter demasiado general acerca de los factores que determinan las decisiones judiciales, dando a entender que los factores que determinan las decisiones judiciales pueden variar dependiendo de los diferentes sectores del ordenamiento. Cfr. TARELlO, 1988: 413.

45 Me refiero al quinto punto del famoso texto «Some Realism about Realism. Responding to Dean Pound». Cfr. Llewellyn, 1931: 1236. 
Según los defensores del attitudinal model, el modelo jurídico tradicional no permitiría explicar ninguna decisión. Antes bien, son razones de tipo político las que mejor capacidad explicativa han demostrado en relación a las decisiones judiciales. El análisis de la adscripción política de los jueces como factor explicativo de las decisiones judiciales habría mostrado una importante capacidad para prever gran parte de las decisiones judiciales. Por tanto, según los defensores del attitudinal model, si bien los realistas clásicos carecieron de los instrumentos metodológicos y del rigor necesario para llevar a cabo predicciones basadas en estudios empíricos a gran escala, su intuición fue buena: la suma de enunciados jurídicos y método jurídico no permite explicar las decisiones judiciales.

Es importante subrayar en este momento que los contornos del New Legal Realism son vagos: si bien hay autores que expresamente se reconocen en tal movimiento (y participaron en uno de esos actos fundaciones tan típicos entre los estudiosos del derecho norteamericanos) ${ }^{46}$, y otros que expresamente se desmarcan de tales posiciones (LEITER), no es del todo claro quiénes son los autores que podemos incluir en tal movimiento ${ }^{47}$. Ello debido a que no es del todo claro cuál es el conjunto de tesis definitorias del movimiento.

Por esta razón, aquí me voy a concentrar sobre todo en las tesis de autores como SunSTEIN, MiLler y CROSS, críticos en alguna medida con el attitudinal model ${ }^{48}$, y defensores de la tesis según la cual el derecho (los enunciados normativos y el modelo de justificación jurídica) constituyen un límite para la decisión judicial.

Para entender la crítica que estos autores dirigen al attitudinal model lo primero que es necesario hacer es aclarar en qué sentido enunciados normativos y método jurídico «limitan las decisiones judiciales».

En un primer sentido, algo banal, método jurídico y enunciados normativos no limitan absolutamente nada: si la mayoría de los jueces decidieran las controversias más allá de lo dispuesto por el derecho, entonces se podría afirmar que las razones jurídicas no limitan en ningún sentido las decisiones judiciales. Antes bien, sería el reproche social o la reacción de otros poderes públicos frente a una violación del contenido del derecho lo que efectivamente limitarían las decisiones judiciales. Sin embargo, resulta bastante poco frecuente que los jueces ignoren sistemáticamente los enunciados normativos y el método jurídico.

46 Vid. ERLANGer et al., 2005.

47 Constituye una figura especialmente singular a estos fines R. POSNER, quien identifica hasta nueve factores que determinarían las decisiones judiciales pero no contempla la posibilidad de que enunciados y método jurídico expliquen al menos algunas decisiones judiciales. Vid. Posner, 2011. Además, el propio PosNER es objeto de alabanzas y críticas por parte de algunos claros exponentes de este movimiento debido a su pasado formalismo. Vid. NOURSE Y SHAFFER, 2009.

${ }^{48}$ Las críticas que dirige CROSs al attitudinal model son, en síntesis, cuatro: i) el muestreo es demasiado reducido, ocupándose sólo de ciertos temas (sobre todo derechos civiles) en los más altos tribunales (Corte Suprema de Estados Unidos); ii) maniqueísmo ideológico: las preferencias políticas de cada juez son identificadas con base en el presidente que los nombró, lo que resulta algo pobre, no permite explicar por qué dichos jueces fallan en ocasiones de manera contraria a tal ideología, en qué medida se ven influidos por sus compañeros de tribunal ni su evolución ideológica; iii) presupone un modelo de racionalidad demasiado simple en el que los jueces aparecen como maximizados de algún bien; y iv) no sirve para explicar cuándo aparecen los votos particulares, los diferentes tipos de sentencias y un paso fundamental como es la admisión a trámite. Vid. Cross, 1997. Pero también Miller y Susntein, 2008. 
En un segundo sentido, es posible preguntarse si las razones jurídicas (enunciados normativos más método jurídico) limitan el conjunto de decisiones posibles en el sentido de que las consideren razones para la acción (aunque no siempre aporten razones concluyentes). Pues bien, lo que sostienen algunos defensores del New Legal Realism —en particular, F. Cross (Cross, 1997) — es que el método jurídico efectivamente limita las decisiones judiciales; no sólo, sino que las razones jurídicas explican completamente algunas decisiones.

El new legal realism tiene en este sentido por lo menos tres virtudes:

i) En primer lugar, vuelve a tomar en cuenta las razones jurídicas como criterios para la explicación de las decisiones judiciales ${ }^{49}$.

ii) En segundo lugar, no pretende ofrecer una única teoría de la decisión judicial que explique toda decisión judicial sino que admite que son factores diferentes los que explican las decisiones en materias y grados del proceso diferentes (MiLlER y SunSTEIN, 2008: 5 y ss.).

iii) En tercer lugar, no sostiene que los jueces son agentes puramente interesados que pretenden maximizar sus propios objetivos sino que aquellos introducen consideraciones valorativas que creen que forman parte del derecho pero que en realidad responden sólo a doctrinas éticas, políticas o jurídicas más o menos dominantes (CrOss, 1997: 294 y ss.).

De este modo, el New Legal Realism parece encontrarse en disposición de combinar el conocimiento tradicional de los juristas acerca de los enunciados normativos y doctrinas sobre el derecho, con las explicaciones causales del attitudinal model. O dicho en términos más clásicos: combinar el conocimiento de la cultura jurídica al estilo de TARELLO, con modelos más sofisticados de predicciones como los del attitudinal model basados en explicaciones no jurídicas.

No obstante, el New Legal Realism tiene también algunos importantes defectos. En particular, antes que combinar explicaciones basadas en razones jurídicas con explicaciones basadas en factores no jurídicos, lo que hace es simplemente yuxtaponerlas. Es decir, y más allá de que realmente las razones jurídicas permitan prever las decisiones judiciales, lo que no hace el New Legal Realism - y parece razonable afirmar que debería hacer- es indicar cuáles son las fuentes de desacuerdo en las razones jurídicas a la hora de decidir un caso, lo que serviría para incorporar las explicaciones basadas en razones jurídicas a métodos de predicción como el attitudinal model.

En efecto, si la decisión de un tipo de casos no depende inmediatamente de un desacuerdo reconducible a alguna ideología política sino de consideraciones teóricojurídicas — como, por ejemplo, si el criterio interpretativo que debe prevalecer es el sistemático o el intencionalista, si el trámite de audiencia a los interesados constituye o no un requisito necesario para la existencia del acto administrativo, o cuáles son los

${ }_{49}$ No ignoro las dificultades que se presentan a la hora de combinar hechos y razones para ofrecer explicaciones. En este sentido, vid. REDONDO, 1996, y DAVIDSON, 1992. No obstante, parece una práctica metodológica no infrecuente en los estudios empíricos de sociología y ciencia política. Por otro lado, me parece que un buen ejercicio de naturalismo filosófico consistiría en dejar de preguntarnos acerca de qué constituye una buena explicación y ver qué consideran los científicos una buena una explicación. Y en este sentido parece que la posibilidad de realizar predicciones exitosas constituye el mayor estándar de explicación posible. 
rasgos definitorios de una tasa respecto de un impuesto- entonces es poco probable que podamos realizar predicciones exitosas utilizando un método como el attitudinal model que presupone que son siempre razones políticas las que determinan las decisiones judiciales.

El problema es precisamente que los jueces, al menos en algunas ocasiones, utilizan alguna de las razones jurídicas en conflicto como razones últimas y concluyentes. Lo que el New Legal Realism podría - y debería - hacer es orientar a politólogos y sociólogos en la identificación de las fuentes de desacuerdo jurídico que permitirían introducir dichos desacuerdos como variables tenidas en cuenta para realizar las predicciones ${ }^{50}$. Es decir, en lugar de compartimentar los métodos para la explicación de decisiones, incorporar las razones jurídicas como factor a tener en cuenta dentro del attitudinal model.

Por supuesto, la anterior constituye una apresurada síntesis de un movimiento heterogéneo todavía en fase de desarrollo. Lo que, no obstante, parece fuera de dudas, es que tomarse en serio la tarea de realizar predicciones requiere una aproximación multidisciplinar, no en el sentido de compartimentar las decisiones jurídicas que serían explicables bajo el attitudinal model y bajo el modelo de las razones jurídicas, sino - como ya propusieron tanto HOLMES como LLEWELLYN - combinando varias aproximaciones al derecho. Bien entendido: no pidiendo a los estudiosos del derecho que manejen los instrumentos del análisis politológico o a los politólogos conociendo las discrepancias internas en las culturas jurídicas de referencia, sino mediante la creación de grupos de trabajo con estudiosos con diversas competencias ${ }^{51}$. Estudiosos que, además, sean capaces de traducir a cada uno de sus áreas de estudio los resultados de tales investigaciones.

\section{RAZONES PARA UNA CIENCIA JURÍDICA REALISTA}

En el apartado anterior he afirmado que los realistas están comprometidos con una teoría predictivista de la ciencia jurídica en la medida en que, fundándose en la tesis de la indeterminación del derecho, sostienen que el factor que determina las decisiones judiciales no es la suma de enunciados normativos y método jurídico sino otros: desde las corazonadas de los jueces, hasta sus aspiraciones profesionales, pasando por las diferentes ideologías jurídicas y políticas. Sin embargo, y con base en los propios postulados empiristas sostenidos por los realistas, para que pudiéramos considerar la teoría realista de la decisión judicial mejor que otras, aquella debería identificar los factores causalmente suficientes que llevan a los jueces a preferir una decisión jurídica en detrimento de las otras soluciones jurídicamente posibles. Ahora bien, dado que si fuéramos capaces de identificar los factores causalmente suficientes de las decisiones judiciales también seríamos capaces de predecir tales decisiones, entonces para que

50 Por ejemplo: no hay ningún meta-criterio último de origen jurídico que le indique al juez Scalia que tiene que adoptar el criterio intencionalista para interpretar la constitución estadounidense. No obstante, aquello que explica gran parte de las decisiones del juez Scalia es que considera la tesis normativa intencionalista como una razón última y concluyente.

51 Para los diferentes significados que puede asumir el concepto de multidisciplinaridad en el campo de los estudios jurídicos, vid. Ost, 1999. 
pudiéramos considerar la teoría realista de la decisión judicial como la más plausible los realistas deberían poder ofrecer predicciones con un elevado índice de acierto. Por tanto, los realistas se encuentran comprometidos teóricamente con ofrecer predicciones sobre cómo decidirán los jueces.

No obstante, no son solo razones de coherencia teórica internas al realismo jurídico las que justifican realizar predicciones sobre cómo decidirán los jueces las futuras controversias. En este último apartado quiero concentrar mi atención en un aspecto al que, en mi opinión, no se ha prestado suficiente atención. Me refiero a las razones de carácter práctico - ético-políticas en sentido amplio- que justificarían la elección de un modelo realista de ciencia jurídica.

\subsection{La necesidad de justificación del modelo realista de ciencia jurídica}

Aducir razones de carácter práctico en favor del modelo realista no constituye una mera curiosidad intelectual o un esfuerzo de imaginación argumentativa. La razón para discutir esta cuestión es que algunos autores han puesto en entredicho el interés de este tipo de estudios considerando que realizar predicciones, si es que fuera posi$b^{52}$, carecería de interés o por lo menos no sería la tarea a la que deberían orientar sus esfuerzos los estudiosos del derecho ${ }^{53}$.

En este sentido, es posible identificar dos problemas diferentes en relación a la justificación práctica del modelo realista de ciencia jurídica. El primero tiene que ver con la justificación que históricamente, en el plano práctico, se ha ofrecido para cultivar el modelo realista de ciencia jurídica ${ }^{54}$. El segundo se refiere a la necesidad de responder a una crítica que, desde posiciones neo-constitucionalistas y/o post-positivistas, se ha dirigido contra todo tipo de positivismo jurídico en general: normativista y realista.

I) El primer problema es que la justificación adoptada por la mayoría de los realistas en favor de este modelo de ciencia jurídica funda tal elección en que podría ser considerado científico, o incluso la única forma científica de conocer el derecho. Es más, se ha llegado a afirmar que sería la única forma posible de conocimiento. Sin embargo, afirmar que el método propuesto por los realistas puede ser calificado como científico no es una razón concluyente para cultivar un modelo realista de ciencia jurídica. Por varias razones.

En primer lugar, porque en sentido estricto no se trata de una razón práctica: que podamos calificar la ciencia jurídica realista como una disciplina científica no es una

52 Aunque utilizo un argumento de KeLSEN para justificar una ciencia jurídica realista predictivista, es preciso señalar que el propio autor consideraba que no es posible realizar predicciones acerca de las futuras decisiones judiciales. Lo único que, según KeLSEN, sería posible prever es la aplicación del derecho válido, lo que — según el propio KELSEN — ya se podría realizar utilizando su modelo de ciencia jurídica. Vid. KeLSEN, 1995: 206-207.

53 L. FERRAJOLI no considera que los estudiosos del derecho no deban realizar predicciones acerca de cómo los jueces decidirán las controversias. Sin embargo, considera que dicha tarea correspondería no a quienes se ocupan de estudiar el contenido del derecho, sino a los sociólogos del derecho. Vid. FerRAJOLI, 2007: 8 y ss.

${ }^{44}$ La afirmación debe ser matizada para el caso de la mayoría de los realistas americanos, como LLEWELLYN, F. COHEN o el propio H. OLIPHANT. Y es que, en el caso de estos autores, lo que se pretendía era conocer cómo efectivamente funcionaba el derecho para mejorarlo. Vid. LLEWELLYN, 1931: 1235. 
razón sino una tesis descriptiva o conceptual. Si de lo que se trata es de ofrecer razones en favor de una doctrina sobre qué deben hacer los estudiosos del derecho, debemos aducir razones prácticas (ético-normativas en sentido amplio), no teóricas.

En segundo lugar, es controvertido que éste sea el único método para estudiar el derecho que podría ser calificado como científico. De hecho, no parece que haya muchos problemas en admitir, desde un punto de vista realista, que existen otros métodos para el estudio del derecho positivo que no tienen pretensiones predictivas y que, sin embargo, pueden ser considerados como científicos (por ejemplo, la kelseniana interpretación científica del derecho) ${ }^{55}$. Si así están las cosas, entonces es necesario ofrecer ulteriores argumentos en favor del modelo predictivista de ciencia jurídica.

En tercer lugar, es posible imaginar estudios desarrollados mediante una metodología científica que, sin embargo, carezcan de interés y que nadie estaría dispuesto a cultivar, incluso aunque tuvieran carácter predictivo. Por ejemplo, predecir cuantas veces aparecerá la letra «a» en una sentencia judicial, por muy basado en un método científico que estuviera, carecería por completo de interés.

Por tanto, el hecho de que se trate de una disciplina científica es una razón —si es que acaso constituye una razón- solamente contribuyente, pero no concluyente, en favor del modelo realista de ciencia jurídica.

II) La segunda causa que provoca esta necesidad de una justificación práctica para la ciencia jurídica realista es la crítica que, desde las filas del post-positivismo, se ha dirigido contra los diferentes positivismos jurídicos. Dicho en extrema síntesis: según autores como ATIENZA y RUIZ MANERO ${ }^{56}$, el positivismo jurídico — tanto como teoría del derecho como las diferentes doctrinas que insisten en que los estudiosos del derecho deben limitarse a describir el contenido del derecho- sería irrelevante pues no ofrece instrumentos suficientes para decidir los casos controvertidos, precisamente aquellos más interesantes. Tomando prestada una metáfora del propio ATIENZA, es como si los positivistas hubieran hecho voto de castidad, absteniéndose de hacer precisamente aquello más interesante, divertido y útil ${ }^{57}$.

Hay sin embargo un pequeño salto argumentantivo en esta crítica: se asume que, para ser relevante, la ciencia jurídica — esta vez en sentido amplio- debe estar mediada por consideraciones de tipo valorativo. Es decir, los estudiosos del derecho deben asumir un método mediado por consideraciones valorativas para que su actividad sea relevante.

El salto está precisamente en equiparar «relevancia práctica» con «mediado por consideraciones valorativas». Ahora bien, del hecho de que una disciplina deba ser relevante se sigue únicamente que debe proporcionar una información que, si fuera conocida por un agente racional, haría que éste la tomara en cuenta como una razón para la acción. Ahora bien, existen muchas disciplinas no mediadas por consideraciones valorativas que son extremadamente relevantes. Por ejemplo, resulta relevante saber

55 P. CHIASSONI defiende que en KELSEN se encontraría un doble modelo de ciencia jurídica realista basado, por un lado, en la interpretación científica kelseniana y, por el otro, en el análisis del conjunto de normas aplicadas por los tribunales. Vid. CHIASSONI, 2012.

56 Vid. Atienza y Ruiz MANERo, 2007.

57 ATIENZA, 2011. 
cuándo se producirá una erupción volcánica, y para ello debemos emplear un método que no incluya juicios de carácter ético-político o moral.

Sin embargo, no es suficiente con rechazar la crítica post-positivista y es necesario ofrecer argumentos que justifiquen por qué los estudiosos del derecho deben adoptar un método como el realista para establecer el contenido del derecho. Los siguientes argumentos están precisamente dirigidos a demostrar que la ciencia jurídica realista es una disciplina relevante para la práctica.

\subsection{La justificación weberiana de la ciencia}

Con el objetivo de analizar las razones que se pueden aducir en favor del modelo realista de ciencia jurídica, voy a analizar dos argumentos ofrecidos por M. WEBER en su famosa conferencia La ciencia como profesión ${ }^{58}$.

A) Podemos sintetizar el primer argumento en favor de un modelo realista de ciencia jurídica del siguiente modo: según WEBER, ningún científico social debe aprovechar su reconocimiento social para avalar sus propias preferencias ético-políticas o prácticas. Esta tesis se funda en un buen argumento: parece poco sostenible afirmar que existen algo así como «expertos morales», de modo que los estudiosos del derecho deberían evitar incorporar consideraciones valorativas en su tarea de determinación del contenido del derecho porque, de este modo, estarían aprovechando su prestigio profesional como científicos para hacer pasar como tesis más plausibles lo que no son sino sus preferencias morales.

Este argumento es susceptible de dos interpretaciones diferentes: en una primera versión, el argumento afirma que nadie que goce de prestigio social en cuanto estudioso del derecho debe aprovechar su rol social para hacer valer sus preferencias éticopolíticas más allá de cualquier discurso sobre el derecho. Ahora bien, en estos términos el argumento resulta decididamente excesivo pues prohibiría a cualquier estudioso hacer cualquier tipo de manifestación acerca de sus preferencias políticas, lo que no parece plausible.

En una segunda versión, más moderada y que presupone la tesis de la indeterminación racional del derecho, el argumento afirma que el estudioso del derecho no debe hacer pasar sus preferencias prácticas como descripciones del derecho. Esto es, si existen varias respuestas jurídicas justificadas y no existen expertos morales, entonces aparecería como injustificado que los juristas recurrieran a consideraciones valorativas pues estarían aprovechando su propia autoridad académica para afirmar que el contenido del derecho debe ser aquél determinado por sus propias preferencias prácticas o morales en sentido amplio.

El problema es que este tipo de justificación no constituye una razón para cultivar el modelo realista de ciencia jurídica, sino cualquier modelo de ciencia jurídica que tenga pretensiones puramente descriptivas, es decir, cualquier modelo de ciencia jurídica en sentido estricto. Por tanto, si existen razones que justifiquen desarrollar una

58 Es importante señalar que WEBER no utiliza estos argumentos en relación a la ciencia jurídica, que es objeto de un análisis del todo diferente. Vid. WEBER, 2008: 221 y ss. 
ciencia jurídica realista, éstas no pueden estar fundadas exclusivamente en la neutralidad axiológica de tal tipo de estudios.

B) Sin embargo, el anterior no es el único argumento, ni tampoco el mejor, que WEBER ofrece para cultivar disciplinas científicas. WEBER presenta otros cuatro argumentos que justificarían dedicar los propios esfuerzos a la ciencia.

i) La ciencia nos permite desarrollar la técnica, es decir, el conocimiento necesario para el dominio del mundo natural y social.

ii) «[L]a ciencia proporciona métodos para pensar, instrumentos y disciplina para hacerlo» (WEBER, 2008: 223).

iii) La ciencia aporta claridad frente a las diferentes posturas prácticas que se pueden adoptar, además del conocimiento de los medios necesarios para conseguir determinados fines y poder conocer las consecuencias de nuestras acciones.

iv) La ciencia permite tomar conciencia sobre las acciones solidarias o coherentes con los propios valores u objetivos que cada persona adopta.

Analizaré cada uno de estos cuatro argumentos por separado para establecer en qué sentido tales argumentos pueden ser aducidos en favor de un modelo realista de ciencia jurídica.

i) Según WeBER, la ciencia sería el conocimiento que nos permite conocer el mundo natural y social para manejarlo y dominarlo. Traducido al ámbito jurídico, la ciencia jurídica realista nos permitiría conocer las consecuencias prácticas de nuestras acciones y, con base en dicha información, orientar instrumentalmente la propia conducta. Es decir, tal conocimiento serviría para orientar nuestra conducta con base en las consecuencias que tendrá aquélla.

Sin embargo, esta primera razón es rechazada por WEBER por fútil: «La ciencia proporciona conocimientos sobre la técnica que, mediante la previsión, sirve para dominar la vida, tanto las cosas externas como la propia conducta de los hombres. Dirán ustedes que por ese camino nos encontramos con la verdulera del muchacho americano; esa es también mi opinión» (WEBER, 2008: 223). Es decir, la utilidad técnica de una disciplina no constituiría una razón suficiente para cultivar una disciplina científica.

ii) En segundo lugar, según WEBER, cultivar cualquier disciplina científica proporciona «métodos para pensar, instrumentos y disciplina para hacerlo» (WEBER, 2008: 223). Ahora bien, esta segunda razón para cultivar la ciencia no parece que sea exclusiva del modelo realista y puede ser reivindicada por todos los modelos de ciencia jurídica, o por cualquier disciplina rigurosa. Además, se podría añadir, antes que ser una tarea de la ciencia, la disciplina que se dedica a clarificar la estructura del pensamiento es la filosofía.

iii) En tercer lugar, según WEBER, la ciencia nos permite conocer las acciones solidarias con nuestras posiciones prácticas y cuáles son los medios idóneos para provocar un determinado efecto en el mundo.

Podemos interpretar este argumento de dos maneras diferentes: en primer lugar, la ciencia nos permitiría conocer las acciones axiológicamente coherentes con nuestros valores; en segundo lugar, como el conocimiento que nos permite identificar los medios necesarios para alcanzar determinados fines. Dado que la primera interpretación coincide con la cuarta razón aportada por WEBER, aquí analizaré únicamente la segunda. 
Parece claro que, en esta segunda interpretación, esta razón es idéntica a la expresada en el primer argumento de WEBER: la ciencia serviría para conocer los medios necesarios para alcanzar determinados objetivos, y orientar la acción con base en dicho conocimiento. Traducido al campo jurídico el argumento es siempre el mismo: lo que justificaría cultivar la ciencia jurídica realista sería la capacidad de conocer las consecuencias de nuestros actos y, de este modo, orientar la propia conducta. Sin embargo, WEBER rechaza esta razón como insuficiente.

iv) En último lugar, según WEBER, la ciencia nos permite conocer las diferentes posturas prácticas que podemos adoptar y que honran nuestros valores (WEBER, 2008: 225). Es decir, la ciencia nos permitiría conocer las acciones que un sujeto debe realizar si quiere ser coherente con sus propios valores o principios.

Sin embargo, parece bastante claro que este tipo de «conocimiento» no nos lo proporcionan las disciplinas científicas sino la filosofía práctica. Y a menos que reduzcamos coherencia axiológica al razonamiento instrumental medios-fines - en cuyo caso terminaría nuevamente colapsando con el aspecto técnico de las ciencias- no se ve cómo la ciencia puede informarnos acerca de la coherencia de nuestras acciones respecto a un conjunto de valores.

Las razones ofrecidas por WEBER resultan por tanto insatisfactorias. Mejor dicho, lo que resulta insatisfactorio es que se deshaga con tanta rapidez del que parece el mejor argumento en favor de cultivar disciplinas científicas en general, y la ciencia jurídica realista en particular: el aspecto técnico de las disciplinas científicas, es decir, la posibilidad de prever las consecuencias de nuestras acciones ${ }^{59}$.

\subsection{Una justificación práctica del realismo jurídico}

Lo que voy a hacer a continuación es ofrecer cuatro argumentos sobre la relevancia moral de conocer las consecuencias de nuestras acciones; en concreto, conocer qué tipo de consecuencias jurídicas es probable que asocien jueces y tribunales a nuestras acciones. Ello porque parece que existen buenas razones para pensar que conocer las consecuencias de nuestras acciones en general, y cómo las calificarán los jueces en particular, tiene relevancia moral.

a) El primer argumento es que es razonable afirmar que tenemos una obligación moral general de conocer - al menos algunas - de las consecuencias de nuestras acciones. En este sentido, no sólo modulamos culpa y/o responsabilidad dependiendo de si la persona conocía las consecuencias de sus actos sino que normalmente aceptamos que los sujetos tienen la obligación de conocer, al menos en algunos ámbitos, las consecuencias de sus acciones. Ahora bien, si las consecuencias de mis acciones dependen,

59 No sostengo que WEBER no concede relevancia la posibilidad de realizar predicciones. Lo que sostengo es que si bien WEBER da importancia a la posibilidad de generar un conocimiento técnico a partir del científico — «Por qué ocuparse de algo [la ciencia] que no tiene ni puede tener nunca un fin? [...] Una primera respuesta es para orientar nuestro comportamiento práctico»- termina descartando una justificación práctica de la actividad científica basada exclusivamente en tal posibilidad: «Tal respuesta es correcta, pero tiene importancia sólo para el hombre práctico». Cfr. WEBER, 2008: 199. Agradezco a D. Moreno que me ha obligado a precisar mis afirmaciones sobre este punto. 
al menos parcialmente, de las futuras decisiones judiciales, entonces tenemos una primera razón de orden moral para investigar cómo decidirán los jueces.

b) El segundo argumento es que la posibilidad de conocer las consecuencias de nuestras acciones es una condición necesaria para poder construir planes de vida. Y poder construir planes de vida constituye un requisito necesario de la autonomía personal. Traducido al campo jurídico esto quiere decir que poder conocer las consecuencias jurídicas de nuestras acciones —qué nos puede suceder realmente si realizamos ciertas acciones- constituye un elemento esencial para autodeterminarnos. Parafraseando a BOBBio: saber si, ejerciendo la desobediencia civil, nos arriesgamos o no a acabar en la cárcel.

c) El tercer argumento constituye en realidad una variante o una consecuencia del anterior. En efecto, uno de los valores fundamentales de nuestras culturas jurídicas es la seguridad jurídica y/o la certeza del derecho. En este sentido, si el derecho está racionalmente indeterminado, al menos en algunas de sus partes, entonces no son las doctrinas acerca de cómo deben decidir los jueces los casos difíciles las que están en mejor posición para garantizar la certeza del derecho. Ello, banalmente, porque los jueces siempre pueden ignorar tales doctrinas o elegir entre doctrinas en competición. Una ciencia jurídica que pretende describir y predecir cómo deciden los jueces es la que se encuentra en mejor posición para garantizar el valor de la seguridad jurídica.

d) El último argumento afirma que los operadores jurídicos, en cuanto administradores directos o indirectos del monopolio institucional de la violencia, tienen un deber moral especial de conocer las consecuencias de sus propias acciones. Ello debido a que el derecho afecta a la mayoría de los bienes y valores morales que consideramos dignos de protección. Tal conocimiento sería proporcionado por la ciencia jurídica realista, el único modelo de ciencia jurídica que específicamente trata de establecer bajo qué condiciones se hará uso de la violencia institucional. Tal conocimiento resulta relevante para varios sujetos.

i) En primer lugar, normalmente se considera que la ciencia jurídica realista sería útil para quien quiere calcular las consecuencias de sus propias acciones y orientar consecuentemente su conducta. En este sentido, la figura del «bad man» (HOLMES, 1975: 18) ha sido frecuentemente asociada con el realismo jurídico. Conocer las consecuencias jurídicas de las acciones tendría así valor moral —ya que afecta o puede afectar a algunos de los bienes que más estima- para quien cumple las normas no porque asume el punto de vista interno, sino porque desea evitar que recaiga sobre él la violencia que administra el derecho.

No obstante, esta afirmación debe ser matizada o completada. Ello porque aquella del bad man es exactamente la misma posición que adoptan los abogados cuando persiguen los intereses de sus clientes. Esto es, la posición que ocupa quien no simplemente debe dar cumplimiento a las normas jurídicas sino que puede, pero sobre todo debe, elegir entre diferentes cursos de acción dependiendo de las consecuencias jurídicas que desea alcanzar.

ii) En segundo lugar, también los propios jueces deberían preocuparse sobre cómo otros tribunales percibirán o interpretarán las decisiones por ellos dictadas. Cuestiones tales como si sus decisiones serán sistemáticamente anuladas por otros tribunales o si pueden llegar a modificar la jurisprudencia consolidada, hacen que los 
jueces tengan un deber moral especial de conocer cómo sus decisiones serán interpretadas, usadas y consideradas jurídicamente por otros tribunales. Además, disponer de tal conocimiento — cómo juzgarán los tribunales superiores sus decisiones- haría que la Administración de justicia fuera más racional.

iii) Por último, conocer las consecuencias de las propias acciones tiene también una relevancia fundamental para quien adopta la posición del «gran reformador» (LLEWELLYN, 1953: 64 y ss.), quien pretende alcanzar determinados fines o efectos mediante el derecho ${ }^{60}$. Es decir, quien pretende cambiar no sólo los enunciados normativos sino modificar las condiciones bajo las cuales se empleará la violencia institucional. Conocer cómo serán interpretados y a qué tipos de decisiones se llegará con base en los enunciados normativos emanados por las autoridades normativas constituye una condición necesaria del éxito de cualquier política o cambio social que deseemos producir mediante el derecho.

\section{BIBLIOGRAFÍA}

AARNIO, A., 1991: Lo racional como razonable, Madrid: CEPC.

AlchourRón, C., y Bulygin, E., 1987: Introducción a la metodología de las ciencias jurídicas y sociales, Buenos Aires: Astrea.

- 1991: Análisis lógico y derecho, Madrid: CEPC.

AleXy, R., 1989: Teoría de la argumentación jurídica, Madrid: CEPC.

ARnOLD, Th., 1930: «Criminal Attempt», Yale Law Journal, núm. 40.

AtienZA, M., 2011: «Sobre constitucionalismo, positivismo jurídico y iusnaturalismo», Teoría Politica, núm. 2.

Atienza, M., y Ruiz Manero, J., 2007: «Dejemos atrás el positivismo jurídico», Isonomía, 27.

BoBBIO, N., 1992: «Essere e dover essere nella scienza giuridica», en N. BOBBIO, Diritto e potere, Napoli: Edizioni Scientifiche Italiane.

- 1996: Il positivismo giuridico, Torino: Giappichelli.

Bulygin, E., 1991a: «Dogmática jurídica y sistematización del derecho», en C. AlCHOurRón y E. Bulygin.

— 1991b: «El concepto de vigencia de Ross», en C. AlChOurRón y E. Bulygin.

Calsamiglia, A., 1990: Introducción a la ciencia del derecho, Barcelona: Ariel.

Castignone, S., 1995: «Realismo americano e realismo scandinavo», en Diritto, linguaggio, realtà, Torino: Giappichelli.

CHIASsOni, P., 1999: La giurisprudenza civile, Milano: Giuffrè.

- 2012: «El realismo radical de Hans Kelsen», en Desencantos para abogados realistas, Bogotá: Universidad del Externado.

CoHen, F., 1959: Ethical Systems and Legal Ideas, New York: Ithaca.

- 1962: El método funcional en el derecho, Buenos Aires: Abeledo-Perrot.

CourTis, C. (ed.) 2006a: Observar la ley, Madrid: Trotta.

— 2006b: «El juego de los juristas», en C. CourTis (ed.).

Cross, F., 1997: «Political Science and the New Legal Realism», Nortbwestern University Law Review, núm. 92.

60 Esta es curiosamente la función que termina atribuyendo KELSEN a la ciencia jurídica o, al menos, a la interpretación científica del derecho. Vid. KELSEN, 2011: 7. 
Cruz Parcero, J. A., 2006: «Los métodos para los juristas», en C. Courtis (ed.): 2006a.

Davidson, D., 1992: «Azioni, ragioni e cause», en Azioni ed eventi, Bologna: Il Mulino.

Douglas, W., 1929: «Vicarious Liability and Administration of Risk I», Yale Law Journal, núm. 38.

Erlanger, H.; Garth, B.; Larson, J.; Mertz, E.; Nourse, V., y Wilkins, D., 2005: «Is it Time for a New Legal Realism», Winconsin Law Review.

Farrell, M. D., 1972: Hacia un criterio empírico de validez, Buenos Aires: Astrea.

Ferrajoli, L., 2007: Principia Iuris, Roma-Bari: Laterza.

FRANK, J., 1949: Law and the Modern Mind, London: Stevens\&Sons.

- 2001: Derecho e incertidumbre, México: Fontamara.

FRIEDMANN, W., 1960: Legal Theory, London: Stevenson.

GREEN, L., 1927: Rationale of proximate cause, Kansas City: Vermon Law Company.

Guastini, R., 2006: Il diritto come linguaggio, Torino: Giappichelli.

- 2011: La sintassi del diritto, Torino: Giappichelli.

HaRT, H., 2004: El concepto de derecho, Buenos Aires: Abeledo-Perrot.

HeRvadA, J., 2002: ¿Qué es el derecho? La moderna respuesta del realismo jurídico, Pamplona: Eunsa.

Holmes, O. W., 1975: La senda del derecho, Buenos Aires: Abeledo-Perrot.

HorwiTz, M., 2004: La trasformazione del diritto americano, Bologna: Il Mulino.

Hutchenson, W., 1929: «The Judgment Intuitive: The Function of the "Hunch" in Judicial Decision», Cornell Law Quarterly, núm. 14.

JAKAB, A., 2011: «Seven Role Models of Legal Scholars», German Law Journal, núm. 12.

JHERING, R. VON, 1987: Bromas y veras en la ciencia jurídica, Madrid: Civitas.

- 1993: La lucha por el derecho, Madrid: Civitas.

- 1995: El fin del derecho, Granada: Comares.

JORI, M., 1976: Il metodo giuridico, Milano: Giuffrè.

Kelsen, H., 1995: Teoría general del derecho y del Estado, México: UNAM.

- 2005: Teoría pura del derecho, México: Porrúa,

— 2011: «Sobre la interpretación», Eunomía, núm. 1.

LEITER, B., 1995: «Legal Indeterminacy», Legal Theory, núm. 1.

— 2007: «Legal Realism and Legal Positivism Reconsidered», Naturalizing Jurisprudence, Oxford University Press.

Llewellyn, K., 1931a: «Some realism about realism. Responding to Dean Pound», Harvard Law Review, núm. 44.

- 1931b: «What Price Contract?», Yale Law Journal, núm. 40.

— 1950: «Remarks on the Theory of Appellate Decision and the Rules or Canons About How Statutes are to Be Construed», Vanderbilt Law Review, núm. 3.

- 1953: Belleza y estilo en el derecho, Barcelona: Bosch.

- 1989: The Case Law System in America, University Chicago Press, Chicago.

- 1991: The Bramble Bush, New York: Oceana.

Martin, M., 1997: Legal Realism, New York: Peter Lang.

Miller, T., y Sunstein, C., 2008: «The New Legal Realism», Chicago Law Review, núm. 75.

Montoro BAllesteros, A., 2007: «Sobre la teoría imperativista de la norma jurídica», Anales de derecho de la Universidad de Murcia, núm. 25.

Neumann, U., 1992: «La teoría de la ciencia jurídica», en A. KAUfMAnN y W. Hassemer (eds.), El pensamiento jurídico contemporáneo, Madrid: Debate. 
NinO, C. S., 1974: Consideraciones sobre la dogmática jurídica, México: UNAM.

- 2003: Algunos modelos de «ciencia» jurídica, México: Fontamara.

Nourse, V., y Shaffer, G., 2009: «Varieties of New Legal Realism: Can a New World Order Prompt a New Legal Theory?», Cornell Law Review, núm. 95.

NúÑEZ VAquero, A., 2013: «Five Models of Legal Science», Revus, núm. 19.

Oliphant, H., 1923: «The Problems of Logical Methods from the Lawyer's Point of View», Proceedings of the Academy of Political Science in the City of New York, vol. 10, núm. 3.

— 1928: «A Return to Stare Decisis», American Bar Association Journal, núm. 14.

Oliphant, H., y HewiTt, A., 1929: «Introduction», en J. RuEFF, From the Physhical to Social Sciences, Oxford University Press.

Olivecrona, K., 1980: El derecho como hecho, Barcelona: Labor.

- 2010: Lenguaje jurídico y realidad, México: Fontamara.

Ost, F., 1999: «Ciencia del derecho», en J. PALOmino Manchego (ed.), Discusión sobre el carácter anti-cientifico del derecho, Lima: Griley.

PATTARO, E., 1971: «Il realismo giuridico come alternativa al positivismo giuridico», Rivista Internazionale di filosofia del diritto, XLVIII.

PECZENIK, A., 2007: Scientia Juris, Dordrecht: Springer.

PÉREZ Lledó, J. A., 2008: El instrumentalismo jurídico americano, Lima-Bogotá: Palestra-Temis.

Posner, R., 2011: Cómo deciden los jueces, Madrid: Marcial Pons.

RATTI, G., 2008: Sistema giuridico, Torino: Giappichelli.

REDONDO, M. C., 1996: La noción de razón para la acción en el análisis jurídico, Madrid: CEPC.

RocA, V., 2008: «La ciencia del derecho en la obra de C. S. Nino», en C. Rosenkratz (ed.), Razonamiento jurídico, ciencia del derecho y democracia en Carlos S. Nino, México: Fontamara.

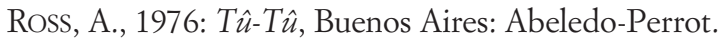

- 1997: Sobre el derecho y la justicia, Buenos Aires: Eudeba.

Rumble, W., 1968: American Legal Realism, Cornell University Press.

SHINER, R., 2010: «Ratio Decidendi», en IVR Enciclopedy. Disponible online en http://ivr-enc. info/index.php?title=Ratio_Decidendi (fecha de consulta: 10 de mayo de 2010).

SPAAK, T., 2009: «Naturalism in Scandinavian and American Realism: Similarities and Differences», en M. DAhlberG (ed.), De Lege: Uppsala-Minnesota Colloquium: law, culture and values, Uppsala: Iustus.

Summers, R., 1982: Instrumentalism and American Legal Theory, Cornell University Press.

Tamanaha, B., 2009: Beyend the Formalist-Realist Divide, Princeton University Press: New Jersey.

TARELLO, G., 1962: Il realismo giuridico americano, Milano: Giuffrè.

- 1974: «Realismo giuridico», en Diritto, enunciati, usi, Bologna: Il Mulino.

- 1988: «La sociologia nella giurisprudenza», en Cultura giuridica e politica del diritto, Bologna: Il Mulino.

VAN HoECKE, M. (ed.), 2011: Methodologies of Legal Research. Wich kiwd of method for which kind of discipline?, Oxford: Hart Publishing.

WeBER, M., 2008: El político y el cientifico, Madrid: Alianza Editorial.

Wroblewski, J., 1989: Contemporary models of legal sciences, Lodz: Polish Academy of Sciences. 